\title{
I. Josef Mengele
}

\section{1911-1943: Kindheit, Karriere, Krieg}

„Der immer noch heftig anbrausende Wind jagte die wie ein dichter Schleier fallenden Schneeflocken in tollen aufbäumenden Wirbeln durcheinander, warf vor die Haustreppen knietiefe Schneewehen, blies an manchen Straßenecken das Katzenkopfpflaster des Marktplatzes blank [...] Fast hilflos klang [...] der Halbstundenschlag vom unteren Torturm, den wenige Sekunden später die Turmuhr der Schloßkirche wiederholte." So beschrieb Josef Mengele in der schwülstig-pathetischen Selbststilisierung, die dem Leser in seinen autobiographischen Aufzeichnungen immer wieder begegnet, den Tag seiner Geburt. Er halte sich an die Erzählungen seiner Eltern, schrieb er, doch offensichtlich wollte er diesen Tag, den Tag der Geburt des Helden, in Anlehnung an alte Erzähltraditionen mit einer besonders bedeutungsschwangeren Aura ausstaffiert sehen. Und obwohl er den Namen seiner Heimatstadt nicht nennt ${ }^{2}$, ist doch für den Ortskundigen in der Beschreibung der lokalen Gegebenheiten die Stadt Günzburg unschwer wiederzuerkennen: Hier also wurde Josef Mengele am 16. März 1911 unter so denkwürdigen klimatischen Umständen als ältester von drei Söhnen des Fabrikbesitzers Karl Mengele ${ }^{3}$ und dessen Frau Wally geboren; hier verbrachte er Kindheit und Jugend, bevor er nach dem Abitur 1930 nach München ging und sich entschloß, Medizin zu studieren. ${ }^{4}$

Nach dem zweiten Semester wechselte er nach Bonn, wo er am 29. Mai 1931 dem Jungstahlhelm beitrat. Im Sommer 1932 bestand er das Physikum, verbrachte das Wintersemester an der Universität Wien und kehrte im Frühjahr 1933 an die Universität München zurück. Dort konzentrierte sich Mengele auf die theoretische Medizin, insbesondere die Genetik und die Anthropologie, und der Direktor des dortigen Anthropologischen Instituts, Theodor Mollison, betreute 1935 Mengeles erste Promotion (Thema: „Rassenmorphologische Untersuchungen des vorderen Unterkieferabschnittes bei vier rassischen Gruppen "5) zum Doktor der Philosophie. Unterdessen war Josef Mengele durch die geschlossene Überführung des Stahlhelms in die SA Mitglied der „Parteiarmee“ geworden, aus der er im Oktober 1934 austrat. 1936 legte Mengele die erste Staatsprüfung ab und absolvierte anschließend sein Me-

1 Sta F/M, Az 4 Js 340/68, Aufz. Mengele, Heft 23: Autobiographisches I, S. 11.

2 Josef Mengele gibt sich in seinen Aufzeichnungen verschiedene Decknamen und schreibt in der dritten Person; in diesem Teil nennt er sein alter Ego „Andreas“. Er „enttarnt" sich aber bald, als er beschreibt, wie sich die Eltern für den „Namen des Nährvaters Christi“ entscheiden. Ebenda, S. 17.

3 Vgl. den Stammbaum der Familie Mengele, Anhang S. 193.

4 Die grundlegenden Daten zu Mengeles Kindheit und Jugend, zu seinen Studienjahren und seinem beruflichen Werdegang bis Ende 1938 liefert ein handgeschriebener Lebenslauf. BAB, BDC, Mengele, Anlage zum R. u. S.-Fragebogen, 1.1.1939. Zu Mengeles Werdegang bis zu seiner Versetzung nach Auschwitz vgl. außerdem Völklein, Mengele, S. 33-92; Zofka, KZ-Arzt, S. 248-255.

5 Mengele, Untersuchungen. 
dizinalpraktikum, zunächst für vier Monate an der Kinderklinik der Universität Leipzig, dann, ab 1. Januar 1937, am von Prof. Otmar Freiherr von Verschuer geleiteten Institut für Erbbiologie und Rassenhygiene in Frankfurt. In Leipzig lernte Mengele seine erste Ehefrau Irene ${ }^{6}$ kennen, die er 1939 heiratete. Mit Beendigung seines Medizinalpraktikums erhielt er die Bestallung als Arzt und wurde zum 1. September 1937 als Assistenzarzt an Verschuers Institut übernommen, wo er 1938 ein zweites Mal promovierte, nun zum Doktor der Medizin (Thema: „Sippenuntersuchungen bei Lippen-Kiefer-Gaumenspalte"7). Im Mai 1937 beantragte Mengele seine Aufnahme in die NSDAP, ein Jahr später die Aufnahme in die SS. Von Oktober 1938 bis Januar 1939 leistete er seinen Wehrdienst bei dem Gebirgsjägerregiment 137/19. Kompanie in Saalfelden/Tirol. Im Sommer 1939 schließlich wechselte er als „Ausbildungsgast" der Klinik für Innere Medizin für ein Semester an die Universität Bonn, erhielt aber weiterhin vom Frankfurter Institut seine Bezüge. ${ }^{8}$

Zum 15. Juni 1940 wurde Josef Mengele zur Wehrmacht einberufen ${ }^{9}$, und von diesem Zeitpunkt bis zu seiner Versetzung nach Auschwitz am 30. Mai 1943 läßt sich sein weiterer Lebensweg nur schwer nachzeichnen. Für diese knapp drei Jahre liegen nur ungenaue und teils widersprüchliche Informationen vor, und entsprechend unzuverlässig und knapp sind die Angaben der bisher erschienenen Biographien für diese Zeit ${ }^{10}$, die - trotz offensichtlicher Widersprüche - auch in einschlägigen Monographien zum Thema Medizin- und Wissenschaftsgeschichte Eingang gefunden haben. Daher sind hier einige Korrekturen erforderlich.

Die in der vorhandenen Literatur gemachten Angaben stützen sich überwiegend auf die Offiziers-Karteikarte in Mengeles SS-Akte. ${ }^{11}$ Dort sind folgende Dienststellungen verzeichnet:
„San. Insp. W. SS 12
Kdt. R./S. Abt. Sip. II ${ }^{13}$
1. $8.40-4.11 .40$
SS-Div. , Wiking ${ }^{\prime 14}$
4.11.40-30. 1.42
SS Inf. Ers. Btl. ,Ost ${ }^{\top 15}$
W./V. Hauptamt, Amtsg. DIII ${ }^{16}$
30. $1.42-22.7 .42$
14. $2.43-30.5 .43$
30. $5.43^{\prime \prime}$

6 Irene Schoenbein, geb. 4. 8. 1917 in Leipzig, Tochter eines aus Fribourg/Schweiz stammenden Kaufmanns; seit 1934 Mitglied im BDM, 1937 Abitur, anschließend Französisch-Studium an der Universität Neuchâtel, später Kunstgeschichte in Florenz. Vgl. Kopie des handschriftlichen Lebenslaufs Irene Schoenbeins, in: Mengele. Dokumentensammlung.

7 Mengele, Sippenuntersuchungen.

8 Vgl. Schreiben Verschuers an das Kuratorium der Universität Frankfurt am Main, 13. 4. 1939, zit. in: Sandner, Universitätsinstitut, S. 90.

9 Die anderen Assistenten Verschuers wurden bereits zu Kriegsbeginn 1939 einberufen; auch Mengele war von Verschuer schon im September „zur anderweitigen Verwendung“ gemeldet worden. Vgl. Schreiben Verschuers an das Kuratorium der Universität Frankfurt am Main, 5. 9. 1939, zit. nach: Sandner, Universitätsinstitut, S. 90. Seine spätere Versetzung hing möglicherweise mit seiner angeschlagenen Konstitution zusammen. Vgl. S. 80.

10 Vgl. Völklein, Mengele, S. 89-92; Posner/Ware, Mengele, S. 35-37; Zofka, KZ-Arzt, S. 254.

11 BAB, BDC, Mengele, Offiziers-Karteikarte.

12 Sanitäts-Inspektion der Waffen-SS.

13 Kommandiert zum Rasse- und Siedlungshauptamt, Sippenamt, Hauptabteilung Sippenamt II. Für die exakte Aufschlüsselung dankt der Verf. Frau Dr. Isabell Heinemann (Universität Freiburg).

14 SS-Division „Wiking“.

15 SS-Infanterie-Ersatz-Bataillon „Ost“.

16 Wirtschafts- und Verwaltungshauptamt der SS, Amtsgruppe D [Konzentrationslager] III [Sanitätswesen und Lagerbygiene]. 
Außerdem berücksichtigt wurden bisher der Bericht von Kurt L., eines Studienfreundes Mengeles, der sich bei den Fahndungsakten der Staatsanwaltschaft in Frankfurt befindet ${ }^{17}$, sowie Angaben Irene Mengeles, auf die sich Gerald Posner und John Ware stützen. ${ }^{18}$

Fest steht das Datum von Mengeles Einberufung zur Wehrmacht, genauer zu dem in Kassel stationierten Sanitäts-Ersatz-Bataillon 9 am 15. Juni 1940. Er verließ diese Einheit am 12. Juli19, nachdem er sich freiwillig zur Waffen-SS gemeldet hatte; laut Kurt L. geschah dies wegen eines schikanösen Ausbilders, „der seine Untergebenen fertigmachen" 20 und dem Mengele auf diesem Wege entkommen wollte. $\mathrm{Ab}$ dem 1. August 1940 wurde er bei der Sanitätsinspektion der Waffen-SS geführt, zunächst im Rang eines SS-Hauptscharführers ${ }^{21}$ der Reserve. Die für das gleiche Datum eingetragene Beförderung zum SS-Untersturmführer ${ }^{22}$ wurde am 2. September 1940 rückwirkend ausgesprochen. ${ }^{23}$

Völklein nimmt in seiner Biographie nun an, Mengele habe in der Zeit vom 1. August bis zum 4. November 1940, also für den Zeitraum, für den die OffiziersKarteikarte als Dienststellung die Sanitätsinspektion der Waffen-SS angibt, eine besondere "militärärztliche Ausbildung" 24 durchlaufen, ohne dafür weitere Belege anzuführen. Die nächste auf der Karteikarte angegebene Dienststellung ist ab dem 4. November 1940 das Rasse- und Siedlungshauptamt, das Mengele als Gutachter „vermutlich bei einer Dienststelle des RKF [Reichskommissar für die Festigung deutschen Volkstums, i.e. Heinrich Himmler] in Posen" 25 einsetzte. Völklein weiß bereits mehr: Mengele sei an der Umsiedlungsstelle in Lodz und an der Einwandererzentralstelle in Posen eingesetzt gewesen. ${ }^{26}$ Mengele war in der Tat in Polen tätig, und seine Dienststelle läßt sich dank eines bisher nicht berücksichtigten Dokuments exakt benennen: Es handelt sich dabei um den Tätigkeitsbericht eines Dr. Heidenreich, der bei der „Gesundheitsstelle der EWZ beim Beauftragten des Reichskommissars für die Festigung deutschen Volkstums“ in Posen „mit dem Kameraden Mengele als erbbiologischen [sic!] Sachverständigen und dem Kameraden Weber als

17 Sta F/M Az 4 Js 340/68, Fahnd.A., Bericht von Kurt L: Mein Freund Josef Mengele.

18 Posner/Ware, Mengele, S. $35 \mathrm{f}$.

19 Vgl. BAB, BDC, Mengele, Offiziers-Karteikarte und ebenda, Formular „Personalangaben“, 18. 7. 1940, von Mengele selbst handschriftlich ausgefüllt.

20 So die Darstellung von Mengeles Studienfreund Kurt L., zit. nach: Völklein, Mengele, S. 89 f.

21 Dies entspricht dem Heeresrang eines Hauptfeldwebels; bei seinem Eintritt in die Waffen-SS wenige Tage zuvor hatte Mengele als Rang noch „SS-Mann“ (ab 1941: SS-Schütze, der niedrigste Mannschaftsdienstgrad) angegeben und war dann vermutlich automatisch in den höchsten Unteroffiziersrang gerückt. BAB, BDC, Mengele, Formular „Personalangaben“, 18. 7. 1940.

22 Dies entspricht dem Heeresrang eines Leutnants.

23 Vgl. BAB, BDC, Mengele, Beförderungsvorschlag betr. Beförderung zum SS-UStuf und Reserveführer, 1. 8. 1940, und ebenda, Schreiben an Mengele betr. Beförderung zum SS-UStuf, 2. 9.1940.

24 Völklein, Mengele, S. 90. Zofka erwähnt im Gegensatz zu Posner/Ware die Dienststellung zumindest (Zofka, KZ-Arzt, S. 254).

25 Zofka, KZ-Arzt, S. 254. Die dort gegebene Auflösung der Abkürzung RKF ist falsch und wurde berichtigt. Zofka verweist auf ein Bild, das Mengele 1940 aus Posen an seine Familie schickte und das ihn als Gutachter in zivil mit zwei Einwanderungswilligen zeigt.

$26 \mathrm{Vgl}$. Völklein, Mengele, S. 90. Leider belegt Völklein insb. den vermuteten Einsatz in Lodz nicht, der sonst meines Wissens nirgends erwähnt wird. 
Psychiater" die "baltendeutschen Großgrundbesitzer und Bauern in erbbiologischer und gesundheitlicher Hinsicht " 27 überprüfte. Mengele war also an der Einwandererzentralstelle in Posen ${ }^{28}$ eingesetzt - nur: Heidenreich arbeitete mit seinem „Kameraden Mengele“ bereits „seit dem 11. August 1940“29 zusammen, und Heidenreichs Bericht datiert vom 7. Oktober 1940. Mengele kann also nicht, wie der Eintrag in seiner Offiziers-Karteikarte nahelegt, erst am 4. November 1940 nach Polen gekommen sein. Vielmehr scheint Mengele bereits an dem Tag, an dem die Offiziers-Karteikarte seine Übernahme in die Sanitäts-Inspektion der Waffen-SS verzeichnet, an der Einwandererzentralstelle (EWZ) tätig oder doch dorthin unterwegs gewesen zu sein: Dies belegt das Schreiben, das die Beförderung des „SSHauptscharführers d. Res. Josef Mengele, z. Zt. E.W.Z. Nordost“ zum SS-Untersturmführer vorschlägt und das das Datum des „1. August 1940“30 trägt.

Wie unzuverlässig die Daten der Offiziers-Karteikarte hinsichtlich der tatsächlichen Einsatzorte Mengeles sind, zeigt auch die nächste Frage: Wann wurde Mengele nach seinem Einsatz in Polen der Waffen-SS-Division Wiking zugeteilt, wann kam er also an die Front? Die Karteikarte nennt hier den 30. Januar 1942 - ein Datum, das oft unkritisch übernommen worden ist ${ }^{31}$, das aber völlig unhaltbar und mit dem Datum von Mengeles Beförderung zum SS-Obersturmführer ${ }^{32}$ identisch ist. ${ }^{33}$ Ebenso falsch ist das Datum des 4. Novembers 1940, das Völklein nennt, wobei es sich hier aber um eine Verwechslung handeln dürfte. Völklein scheint von der Offiziers-Karteikarte versehentlich das eine Zeile höher eingetragene Datum für Mengeles Kommandierung zum RuSHA übernommen zu haben, schreibt er doch nur sechs Zeilen zuvor, Mengele habe „bis Anfang November 1940“ die oben bereits erwähnte truppenärztliche Ausbildung erhalten und sei dann in Polen eingesetzt worden - kaum hätte er dann schon am 4. November zur Division Wiking stoßen können. Zusätzlich widerlegt wird das Datum auf der Offiziers-Karteikarte durch ein Schreiben, das den „SS-Untersturmführer d. Res. Josef Mengele, z. Zt. Arzt SS-Div.-,Wiking' SS-Pi.-Batl. 5 “34 zur Beförderung vorschlägt und das Datum des 24. Novembers 1941 trägt. Kurt L., Mengeles Studienfreund und inzwischen Trup-

$27 \mathrm{BAB}, \mathrm{R}$ 69/455, Bl. 18-23, Bericht des Dr. Heidenreich über seine Tätigkeit bei der Gesundheitsstelle der EWZ, 7. 10. 1940, Zitat Bl. 18. Auf dieses Dokument haben schon 1994 Götz Aly und Susanne Heim am Rande hingewiesen, ohne daß es bisher in Biographien Mengeles Berücksichtigung gefunden hätte (vgl. Aly/Heim, Vordenker, S. 164).

28 Vgl. grundlegend zu Mengeles Gutachtertätigkeit bei der Dienststelle des Reichskommissars für die Festigung deutschen Volkstums (RKF), Heinrich Himmler: Aly/Heim, Vordenker, S. 163-168; Aly, Endlösung, S. 374-382.

$29 \mathrm{BAB}, \mathrm{R} 69 / 455, \mathrm{Bl}$. 18-23, Bericht des Dr. Heidenreich über seine Tätigkeit bei der Gesundheitsstelle der EWZ, 7. 10. 1940, Zitat Bl. 18.

$30 \mathrm{BAB}, \mathrm{BDC}$, Mengele, Beförderungsvorschlag betr. Beförderung zum SS-UStuf und Reserveführer, 1. 8. 1940.

31 Vgl. Zofka, KZ-Arzt, S. 254, und Posner/Ware, Mengele, S. 36. Posner/Ware haben offensichtlich ebenfalls Probleme mit den widersprüchlichen Angaben, denn sie belegen zwar mit einem Brief Irene Mengeles, daß Mengele bereits im Sommer 1941 an der Ostfront gewesen sei (s. u.), schreiben dann aber wenig später, Mengele sei erst im Januar 1942 zur Division Wiking gestoßen.

32 Dies entspricht dem Heeresrang eines Oberleutnants.

33 Vgl. neben dem Eintrag auf Mengeles Offiziers-Karteikarte: BAB, BDC, Mengele, Schreiben an Mengele betr. Beförderung zum SS-OStuf, 30. 1. 1942.

$34 \mathrm{BAB}, \mathrm{BDC}$, Mengele, Beförderungsvorschlag betr. Beförderung zum SS-OStuf, 24. 11. 1941. 
penarzt bei der 198. Infanterie-Division, traf Mengele im Sommer 1941 zudem überraschend in der Ukraine: „Wir waren vor der von den sowjetischen Truppen zerstörten Brücke von Dnjepropetrowsk in Wartestellung eingewiesen worden. Neben uns lag eine SS-Division mit dem Zeichen des Sonnenrades (Wiking). Ich wußte durch eine Nachricht seiner Angehörigen, daß J. M. bei einer solchen Division im Einsatz sein könne. Auf meine Nachfrage beim Wachposten wurde ich tatsächlich etwa hundert Meter weiter zu ihm geführt. “35 Bestätigt wird dies durch die Angaben Irene Mengeles in einem Brief, in dem sie im August 1941 schrieb, ihr Mann habe „endlich den ersehnten Gestellungsbefehl“. Sie nehme an, er sei in der Ukraine stationiert. In dieser Hitze, [und] schon in den ersten Tagen habe er das EK II bekommen. ${ }^{36}$ Beide Angaben sind auch deshalb glaubwürdig, weil Mengeles Division und L.s Einheit von Ende Juli bis Ende September wirklich in Abwehrkämpfe am Brückenkopf Dnjepropetrowsk verwickelt waren. ${ }^{37}$ Mengele war also bereits im Sommer 1941 bei der Division „Wiking“, obwohl ihn seine OffiziersKarteikarte immer noch als zum RuSHA kommandiert führt.

Bleibt die Frage, wann Mengele nun zur Division „Wiking“ versetzt wurde. In einer Beurteilung Mengeles aus dem Jahr 1944 schreibt der SS-Standortarzt von Auschwitz, Eduard Wirths, Mengele habe sich „während des Ostfeldzuges von Juni 1941 bis Juni 1943 glänzend bewährt" 38 . Nun hat Mengele definitiv nicht bis Juni 1943 am Ostfeldzug teilgenommen, sondern war spätestens Ende Januar 1943 zurück in Berlin (dazu später mehr). Es spricht aber nichts dagegen, anzunehmen, daß zumindest die Aussage Wirths' richtig ist, Mengele habe den Rußlandfeldzug, der am 22. Juni 1941 begann, von Anfang an mitgemacht. Die Entscheidung zur Aufstellung der SS-Division „Wiking" fiel mit Wirkung vom 1. Dezember 1940, im Februar/März 1941 wurde die zum Teil aus bereits bestehenden Einheiten ${ }^{39}$ neu aufgestellte Division auf einem Truppenübungsplatz zusammengezogen, wo sie nach ihrer Eingliederung in die Heeresgruppe $\mathrm{C}$ bis Ende Mai stationiert war. Es spricht vieles dafür, Mengeles Versetzung in diese Zeit, also irgendwann zwischen Februar und Mai, spätestens jedoch Juni 1941 zu datieren und somit davon auszugehen, daß Mengele am Rußlandfeldzug von Anfang an teilgenommen hat. Bei ihrem Vormarsch auf sowjetischem Gebiet war die Division Wiking vermutlich an Massenmorden an Kriegsgefangenen und Zivilisten beteiligt, so etwa an einem Massaker an 600 Juden in Zborow. 40

Die nächste Eintragung auf Mengeles Offiziers-Karteikarte, die einen Stellungswechsel betrifft, ist eine Versetzung Mengeles zur Dienststelle des Reichsarztes SS und Polizei mit Sitz in Berlin. Völklein scheint sich erneut in der Zeile geirrt zu haben, denn er datiert Mengeles „Abschied von der Truppe nach einer leichten Ver-

35 Bericht von Kurt L., zit. nach Völklein, Mengele, S. 91.

36 Posner/Ware, Mengele, S. 35, nach einem Brief Irene Mengeles an Hr. Wahl, 15. 8. 1941.

37 Seit 28. 6. 1941 hielt sich die Division Wiking bereits im Raum Dnjepropetrowsk auf und war zunächst mit Verfolgungskämpfen befaßt. Vgl. Tessin, Verbände, S. 321-324, und Klietmann, Waffen-SS, S. 133-142.

38 BAB, BDC, Mengele, Beurteilung des SS-Hstuf Dr. Josef Mengele, 19. 8. 1944.

39 SS-Regiment „Germania“, SS-Regiment „Nordland“, SS-Regiment „Westland“. Die SSStandarte Nordland rekrutierte ihr Personal hauptsächlich aus Freiwilligen aus Dänemark und Norwegen, die SS-Standarte „Westland“ hauptsächlich aus Flamen und Niederländern.

40 Vgl. Pohl, Judenverfolgung, S. 70. 
wundung" 41 auf den 30. Januar 1942, koinzidierend mit dem Datum der Beförderung zum SS-Obersturmführer. ${ }^{42}$ Richtig ist, daß Mengele irgendwann während seines Einsatzes verwundet worden sein muß, denn er erhielt im Laufe seines Einsatzes an der Ostfront das Verwundetenabzeichen in Schwarz. ${ }^{43}$ Einiges spricht dafür, diese Verwundung auf den Juli 1942 zu datieren, denn am 17. dieses Monats tauschte Josef Mengele mit einem anderen SS-Arzt den Posten und wurde - offiziell - zur Dienststelle des Reichsarztes SS und Polizei versetzt. ${ }^{44}$ Von der Dienststelle Reichsarzt SS und Polizei soll Mengele dann erneut als Gutachter an das Rasseamt des RuSHA abgestellt und in Polen eingesetzt worden sein; seine Aufgabe sei die Kategorisierung der polnischen Bevölkerung nach rassischen Kriterien im Hinblick auf ihre „Eindeutschungsfähigkeit" gewesen..$^{45}$ Leider bieten weder Posner und Ware noch Völklein einen Beleg für diese Aussage ${ }^{46}$, möglicherweise liegt eine Verwechslung mit Mengeles erstem Einsatz in Polen vor; Vermutungen, Mengele habe bereits bei der Dienststelle des Reichsarztes SS und Polizei, die auch für die Beaufsichtigung der medizinischen Versuche in den KL zuständig war, „Einblick in die Vorgänge in den KL gewonnen “47 und ihm sei „bereits in einer frühen Phase das Geheimnis der Endlösung anvertraut worden “48, sind deshalb Spekulation. Was genau Mengeles Aufgabengebiet beim Reichsarzt SS und Polizei war und wo genau er eingesetzt war, ist

41 Völklein, Mengele, S. 90.

42 Völklein spekuliert, Mengele habe auf Grund einer Verwundung die Truppe verlassen und sei aus diesem Anlaß zum SS-OStuf befördert worden. Dabei überschätzt er die Geschwindigkeit der SS-Bürokratie bei Beförderungsanträgen. Zudem hatte der Chef des Sanitätsamtes der SS, Brigadeführer Genzken, Mengele bereits im November 1941 zur Beförderung vorgeschlagen. Da dieser Beförderungsvorschlag ohne weitere Begründung blieb, dürfte es sich um eine turnusgemäße Beförderung gehandelt haben, die dann anläßlich des Jahrestages der Machtergreifung vorgenommen wurde. Vgl. BAB, BDC, Mengele, Beförderungsvorschlag betr. Beförderung zum SS-OStuf, 24. 11. 1941. Im Gegensatz dazu steht Mengeles Beförderung zum SS-HStuf, die auf den Vorschlag von Mengeles Bataillonskommandeur zurückging, ausführlich begründet war und durch den Divisionsarzt unterstützt wurde: „Besonders tüchtiger Truppenarzt. Beförderung wird wärmstens befürwortet!“ Ebenda, Beförderungsvorschlag betr. Beförderung zum SS-HStuf, 13. 10. 1942. Auch diese Beförderung wurde dann anläßlich eines markanten Datums vorgenommen, nämlich am 20.4. 1943, dem Führergeburtstag. Ebenda, Schreiben an Mengele betr. Beförderung zum SS-HStuf, 16. 4. 1943.

43 Wirths erwähnt dies in seiner bereits zitierten Beurteilung; vgl. BAB, BDC, Mengele, Beurteilung des SS-Hstuf (R) Dr. Josef Mengele, 19. 8. 1944. Das Verwundetenabzeichen wurde in drei Stufen vergeben: Schwarz, Silber und Gold.

44 Vgl. BAB, BDC, Mengele, Personalbefehl, 17. 7. 1942.

45 Durch die Erstellung der sog. „Deutschen Volksliste“ (DVL) sollte die Bevölkerung in „Deutschstämmige“ und „Fremdvölkische“ geschieden und „rassisch wertvolle“ und „nordisch germanische“ Bevölkerungsteile erkannt, herausgelöst und „eingedeutscht" werden. Es gab vier Kategorien, in die die polnische Bevölkerung eingeordnet wurde (Reichsbürger, Deutsche Staatsangehörige, Deutsche Staatsangehörige auf Widerruf, Schutzangehörige); darunter wäre noch eine fünfte Kategorie anzusiedeln, der vor allem Juden und Zigeuner zugehörten und für die überhaupt kein rechtlich definierter Status existierte. Viele Angehörige der Gruppe 3 wurden als Zwangsarbeiter ins Altreich deportiert, die Angehörigen der Gruppe 4 meist in eines der Vernichtungslager. Nach: Harten, De-Kulturation, S. 99-121. Vgl. zur DVL außerdem: Broszat, Polenpolitik, S. 118-137; Madajczyk, Okkupationspolitik, S. 454-478.

46 Vgl. Posner/Ware, Mengele, S. 36, und Völklein, Mengele, S. 91.

47 Zofka, KZ-Arzt, S. 254.

48 Posner/Ware, Mengele, S. 36. 
nicht geklärt - wenn er denn überhaupt je seinen Dienst für den Reichsarzt SS und Polizei angetreten hat. Einiges deutet nämlich darauf hin, daß Mengele seine Einheit zumindest im Juli 1942 tatsächlich überhaupt nicht verlassen hat.

Am 13. Oktober 1942 schlug der Kommandeur des SS-Pionierbataillons 5, unterstützt durch den Divisionsarzt der Division „Wiking“, Josef Mengele zur Beförderung zum Hauptsturmführer vor. Begründet wurde der Beförderungsvorschlag mit der „volle $[n]$ Erfüllung seiner Dienststellung als Truppenarzt des SS-Pi. Batl. 5“, und natürlich wollte man diesen "besonders tüchtige [n] Truppenarzt" behalten, weshalb man sich für eine Verwendung „in bisherige Dienststellung [sic!] “49 aussprach. Noch deutlicher wird ein beigeheftetes Blatt, das die wichtigsten Dienstdaten Mengeles zusammenfaßt und Mengeles derzeitige Dienststellung mit „Batl. Arzt ${ }^{\circ 50}$, also Batallions-Arzt und damit einer militärischen Einheit der Waffen-SS angehörig, angibt.

Das wichtigste Indiz, das gegen eine Rückkehr Mengeles von der Ostfront schon im Juli 1942 spricht, ist ein Brief, den Mengeles Frankfurter Mentor Prof. Otmar Freiherr von Verschuer, der am 1. Oktober 1942 die Leitung des Kaiser-WilhelmInstitutes (KWI) für Anthropologie in Berlin übernommen hatte, am 25. Januar 1943 an seinen Vorgänger, Prof. Eugen Fischer, schrieb. Darin heißt es:

„Vor wenigen Tagen ist mein Assistent Mengele in 2 Tagen von Salsk ${ }^{51}$ im Flugzeug nach Deutschland gekommen. Er hat bei der SS-Division, Wiking' die ganzen Kämpfe mitgemacht, ist mit dem EK I ausgezeichnet und zunächst zu einer Dienststelle hier nach Berlin versetzt, so daß er daneben am Institut etwas tätig sein kann. Er erzählte sehr interessant, daß das ganze Unglück links und rechts von Stalingrad durch den Zusammenbruch der rumänischen Armee zustande gekommen sei. “52

Dieser Brief zählt in Sachen Mengele zu den Standardquellen, und kaum ein Werk zur Medizin- oder Wissenschaftsgeschichte, das sich mit Josef Mengele und der Rolle der deutschen Wissenschaft im Nationalsozialismus befaßt, kommt ohne die Stelle dieses Briefes aus, die eine Zusammenarbeit Verschuers und damit des KaiserWilhelm-Instituts mit Mengele bereits vor dessen Versetzung nach Auschwitz belegt („daneben am Institut etwas tätig sein kann“). Oft genug folgt dieser Satz einer Kurzbiographie Mengeles, in der es nur wenige Seiten (oder gar Zeilen) zuvor heißt, Mengele habe die Front im Juli 1942, also ein halbes Jahr (!) vor Verschuers Brief, verlassen..$^{53}$ Dieser Widerspruch blieb bisher unkommentiert. Mengele kam also, schenkt man Otmar von Verschuer Glauben, erst Mitte Januar 1943 von der Front zurück nach Berlin. ${ }^{54} \mathrm{Daß}$ Verschuer eine solche Geschichte erfunden oder Mengele

$49 \mathrm{BAB}, \mathrm{BDC}$, Mengele, Beförderungsvorschlag betr. Beförderung zum SS-HStuf, 13. 10. 1942.

50 BAB, BDC, Mengele, Beiblatt zum Beförderungsvorschlag zum SS-HStuf, 13. 10. 1942.

51 Die Stadt befindet sich ca. $150 \mathrm{~km}$ südöstlich von Rostow und ca. $400 \mathrm{~km}$ südwestlich von Stalingrad.

52 Brief von Verschuers an Eugen Fischer, 25. 1. 1943, zitiert nach: Lösch, Rasse, S. 406.

53 So z. B. bei: Posner/Ware, Jagd, S. 37; Müller-Hill, Wissenschaft, S. 112; Zofka, KZ-Arzt, S. 254, und zuletzt bei Sachse/Massin, Forschung, S. 25.

54 Eine Mitteilung von Verschuers vom 29. 6. 1943 über die im Rechnungsjahr 1942 erzielten Einnahmen aus Gutachten, in der auch Josef Mengele erscheint, kann nicht als Beleg angeführt werden, daß Mengele bereits 1942 in Berlin und für das KWI tätig war, wie z. B. Klee dies tut (Klee, Auschwitz, S. 457). Das Dokument stammt vom 29.6. 1943 und umfaßt nicht nur die Einnahmen des Jahres 1942, sondern alle Einnahmen seit Verschuer das Institut am 
seinem Mentor ein derartiges Lügenmärchen aufgetischt haben könnte, darf wohl als ausgeschlossen gelten. Immerhin zeigt sich Verschuer in seinem Brief über die katastrophale Lage in Stalingrad gut informiert - was er Mengeles Bericht zu verdanken haben dürfte - und äußert sich beinahe defaitistisch. ${ }^{55}$

Verschuers Angabe wird durch ein weiteres Dokument gestützt, das bisher noch nicht in die Literatur Eingang gefunden hat: Eine eidesstattliche Erklärung Dr. Horst Fischers ${ }^{56}$, der Mengele bei der Division Wiking kennengelernt ${ }^{57}$ und später in Auschwitz wieder getroffen hat. Fischer erklärte, Mengele habe „den Vormarsch der Division, Wiking als Truppenarzt der Pionierabteilung bis zum Fluß Terek

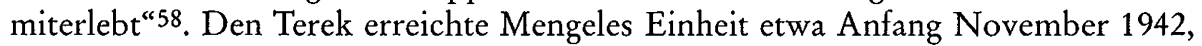
einen Monat später begann sie den Rückzug und befand sich im Januar wieder im Gebiet um Salsk ${ }^{59}$ - eben dort, wo Mengele laut Verschuer Mitte Januar 1943 ein Flugzeug bestiegen hatte, um nach Berlin zurückzukehren.

Als letztes Indiz für Mengeles Verbleiben an der Front können einige Angaben gelten, die Posner und Ware offenbar gestützt auf die Erinnerung Irene Mengeles machen: Sie schreiben, Mengele habe sein Eisernes Kreuz I. Klasse in den Kämpfen um Rostow und Bataisk erhalten und Irene Mengele erinnere sich, daß er zwei verwundete Soldaten unter Feindbeschuß aus einem brennenden Panzer gerettet habe. ${ }^{60} \mathrm{Ob}$ die zeitlichen Angaben ebenfalls von Mengeles Ehefrau stammen, bleibt etwas unklar, ist aber wahrscheinlich, da sich der ganze Abschnitt überwiegend auf ihre Angaben stützt. Mengeles Einheit nahm vom 21. Juli 1942 bis zum 25. Juli $1942^{61}$ an der "fünf Tage währenden blutigen Schlacht um Rostow und Bataisk"62 teil, jedenfalls nach dem Personalbefehl vom 17. Juli, der die Versetzung zur Dienststelle Reichsarzt SS und Polizei anordnete. ${ }^{63}$ Dementsprechend schreiben Posner

1. 10. 1942 übernommen hatte (vgl. Lösch, Rasse, S. 407); auch Benoit Massin teilt diese Ansicht, für dessen Präzisierung der etwas ungenauen Angabe in Sachse/Massin, Wissenschaft, S. 25 f., der Verf. dankt.

55 „Unsere Hoffnung, daß Stalingrad sich bis zum Entsatz halten kann, ist [...] sehr geschwunden. Der Gedanke, daß eine ganze dt. Armee in die Hände der Bolschewisten kommt, ist einfach furchtbar". Brief von Verschuers an Eugen Fischer, 25. 1. 1943, zitiert nach: Lösch, Rasse, S. 406.

56 BStU, MfS, ZA, ZU V 84, HA Bd. 5, Bl. 301-308, Eidesstattliche Versicherung Dr. Horst Fischers, 16. 5. 1966. Die Angaben Fischers, der sein Verhältnis zu Mengele als „kameradschaftlich und gut" (ebenda, Bl. 302) bezeichnet, sind, soweit sie verifiziert werden konnten, zuverlässig. Fischer war nach dem Krieg in der DDR untergetaucht und 1966 zum Tode verurteilt worden (Urteil des Obersten Gerichts der DDR, 25. 3. 1966, Az 1Zst(I)1/66. Nach: Justiz und NS-Verbrechen, laufende Verfahrensnummer 1060). Für den Hinweis auf dieses Dokument danke ich Ulrich Völklein.

57 Die beiden hatten sich anläßlich einer Besprechung beim Divisionsarzt nur „sehr oberflächlich und kurz" kennengelernt (BStU, MfS, ZA, ZU V 84, HA Bd. 5, Bl. 302).

58 Ebenda.

59 Vgl. Klietmann, Waffen-SS, Karte S. 135; die Einheit hielt sich zwar auch im Juli 1942 auf dem Vormarsch im selben Gebiet auf, als Mengele angeblich zum Reichsarzt SS und Polizei versetzt wurde, eine wie auch immer geartete Verwechslung auf Seiten Verschuers oder eine Fehldatierung des Briefes ist jedoch durch den Bezug auf die Schlacht von Stalingrad völlig ausgeschlossen.

60 Vgl. Posner/Ware, Mengele, S. 36.

61 Vgl. Klietmann, Waffen-SS, S. 136.

62 Posner/Ware, Mengele, S. 36.

63 Verwunderlich ist allerdings, daß Mengeles EK I, wenn er es tatsächlich Ende Juli erhalten 
und Ware weiter, Mengele sei „gegen Ende des Jahres 1942“64 von der Front zurückgekehrt. Damit befinden wir uns in großer zeitlicher Nähe zu Mengeles wahrscheinlicher Rückkehr Mitte Januar 1943; ein Irrtum Irene Mengeles in der Größenordnung von einigen Wochen wäre durchaus denkbar - demnach spräche auch die Erinnerung seiner Ehefrau für eine Rückkehr Mengeles von der Front erst im Januar 1943.

Es kann also als gesichert gelten, daß Mengele sich mindestens in der Zeit von Oktober 1942 (dem Datum des Beförderungsvorschlags) bis Januar 1943 wieder an der Ostfront bei der SS-Division "Wiking" befand. Höchstwahrscheinlich hat er diese jedoch gar nicht erst verlassen und ist erst Mitte Januar endgültig nach Berlin zurückgekehrt. Seine Verletzung kann nicht zuverlässig datiert werden. Sollten die Angaben Irene Mengeles bei Posner und Ware richtig sein, denen zufolge Mengele an der Schlacht um Rostow und Bataisk teilgenommen haben soll, kann der Auslöser für die Versetzung zum Reichsarzt SS und Polizei, die einige Tage vorher angeordnet wurde, nicht eine Verwundung gewesen sein. Die Tatsache, daß Mengele am 14. Februar 1943 offiziell zum SS-Infanterie-Ersatz-Bataillon „Ost“ versetzt wurde ${ }^{65}$, spricht vielmehr dafür, daß Mengele erst kurz vor diesem Zeitpunkt verwundet wurde, da es sich bei solchen Ersatzbataillonen um Ausbildungs- und Rekonvaleszenz-Einheiten handelte. Deshalb und angesichts des extrem geringen Aussagewertes der Angaben auf Mengeles Offiziers-Karteikarte hinsichtlich der tatsächlichen Einsatzorte muß es als äußerst fraglich gelten, ob die Versetzung Mengeles zur Dienststelle Reichsarzt SS und Polizei außer auf dem (bekanntlich geduldigen) Papier überhaupt stattgefunden hat, zumal sich für eine wie auch immer geartete Tätigkeit für diese Dienststelle bisher keine Belege außerhalb von Mengeles SS-Personalakte finden lassen - ganz im Gegensatz zu einem Verbleib bei seiner Einheit an der Ostfront.

Die Tatsache, daß die Angaben zu Mengeles Dienststellungen auf seiner Offiziers-Karteikarte und in den Personalbefehlen nicht annähernd mit seinen durch andere Belege eindeutig gesicherten Einsatzorten übereinstimmen, kann hier nur konstatiert, jedoch nicht erklärt werden. Hier sei noch auf eine Besonderheit bei Mengeles letztem Versetzungsbefehl hingewiesen. Befohlen wird dort die „Inmarschsetzung zum K.L. Auschwitz b. Kattowitz, Meldung beim Lagerkommandanten "66. Kein Versetzungsbefehl in Mengeles Personalakte, abgesehen von der gerade zitierten Kommandierung nach Auschwitz, enthält auch einen Marschbefehl;

haben sollte, in dem letzten Beförderungsvorschlag zum SS-HStuf vom 13. 10. 1943 unter „Auszeichnungen“ nicht aufgeführt wurde, dort werden lediglich „EK II, Ostmedaille“ genannt (BAB, BDC, Mengele, Beförderungsvorschlag betr. Beförderung des SS-OStufs Josef Mengele zum HStuf, 13. 10. 1942). Sollte Irene Mengele sich geirrt und Mengele das EK I erst später erhalten haben, würde das allerdings ebenso Mengeles weiteren Verbleib an der Front belegen. Das Eiserne Kreuz II. Klasse hatte Mengele bereits im Sommer 1941 erhalten (s. o.), die Ostmedaille wurde allen Soldaten verliehen, die an den Winterkämpfen 1941/42 an der Ostfront teilgenommen hatten. In Anspielung auf die desolate Winterausrüstung nannten die Soldaten die Auszeichnung den "Gefrierfleischorden“.

64 Posner/Ware, Mengele, S. 36.

65 BAB, BDC, Mengele, Befehl betr. Versetzung des SS-OStufs Josef Mengele zum SS-Inf. Ers. Btl. „Ost“, 14. 2. 1943.

66 BAB, BDC, Mengele, Befehl betr. Versetzung des SS-Hstuf Josef Mengele zum W. u. V.Hauptamt, Amtsgruppe D III, 24. 3. 1943. 
gleichzeitig ist dieser Befehl der einzige, für den eine wirkliche Änderung der Dienststelle zum genannten Zeitpunkt nachgewiesen und auch durch andere Quellen belegbar ist. Möglicherweise spiegeln die Angaben auf der Offiziers-Karteikarte hauptsächlich verwaltungsinterne Vorgänge, die sich auf die tatsächliche Dienststellung des Betroffenen nicht zwangsläufig konkret auswirkten.

Zusammenfassend läßt sich sagen, daß Josef Mengele im Juli 1940 zur Waffen-SS kam und spätestens seit Anfang August für das RuSHA an der Einwandererzentralstelle Nord-Ost in Posen als Gutachter tätig war, und zwar mindestens bis zum 7. Oktober des gleichen Jahres, wahrscheinlich jedoch bis zum Frühjahr oder Frühsommer 1941. Irgendwann in dieser Zeit wurde Mengele als Truppenarzt zur SSDivision Wiking, genauer gesagt, zu dem dieser Division unterstellten SS-PionierBataillon 5 versetzt. Mit dieser Einheit nahm er, höchstwahrscheinlich von Anfang an, am Rußlandfeldzug teil, erhielt mehrere Auszeichnungen und wurde zu einem nicht genau feststellbaren Zeitpunkt verwundet. Ein Beleg für eine Versetzung zur Dienststelle Reichsarzt SS und Polizei im Juli 1942 konnte nicht gefunden werden, ebensowenig wie Belege für eine nochmalige Tätigkeit Mengeles als Rassengutachter für das RuSHA. Beides kann für die Monate August/September 1942 auch nicht mit letzter Sicherheit ausgeschlossen werden, obwohl die Indizien für einen Verbleib Mengeles bei seiner Einheit auch während dieser Monate sprechen. Spätestens im Oktober befand sich Mengele sicher wieder an der Front. Wahrscheinlich hat er die bereits erwähnte Verwundung erst relativ kurz vor seiner Ankunft in Berlin im Januar 1943 erhalten, sie dürfte ursächlich für seine Rückkehr von der Front und seine Versetzung zum SS-Infanterie-Ersatz-Bataillon „Ost“ gewesen sein. Während seines Aufenthaltes in Berlin war Mengele, wie bereits angedeutet, in seiner Freizeit für Verschuers Kaiser-Wilhelm-Institut ${ }^{67}$ (KWI) tätig und wurde am 20. April zum SS-Hauptsturmführer ${ }^{68}$ befördert.

Als Ende Mai der Lagerarzt des Zigeunerlagers in Auschwitz-Birkenau, Benno Adolph, an Scharlach erkrankte und absehbar war, daß er für längere Zeit dienstunfähig bleiben würde, griff man auf den bei der Ersatzeinheit wartenden Josef Mengele zurück. ${ }^{69}$ Mit Wirkung zum 30. Mai wurde er zum Wirtschafts- und Verwaltungshauptamt der SS, Amtsgruppe DIII70, versetzt: „Inmarschsetzung zum K.L. Auschwitz b. Kattowitz, Meldung beim Lagerkommandanten. “71

${ }^{67}$ Vgl. zum KWI unter der Leitung von Verschuers und der Zusammenarbeit mit Mengele vor und nach dessen Versetzung nach Auschwitz: Lösch, Rasse, S. 392-417, und Sachse/Massin, Forschung, S. 23-28.

68 Dies entspricht dem Heeresrang eines Hauptmannes. Dic Beförderung erfolgte erneut an einem markanten Datum, dem Geburtstag Adolf Hitlers.

69 Vgl. Völklein, Mengele, S. 92.

70 Durch Zusammenlegung verschiedener Vorgängerämter entstand am 1.2.1942 das WVHA unter der Leitung von Oswald Pohl, dem seit dem 16.3.1942 auch die Inspektion der Konzentrationslager in Oranienburg als Amtsgruppe D unterstand. Das Amt D III war zuständig für das Sanitätswesen und die Lagerhygiene. Vgl. dazu Orth, System, S. 162-169; Tuchel Inspektion, S. 84-93 und 152-163; Schulte, Zwangsarbeit.

71 BAB, BDC, Mengele, SS-Offiziers-Karteikarte und Schreiben des SS-Führungshauptamtes, Amtsgruppe D an das SS-Inf.Ers.Bat. „Ost“ betr. Dienstversetzung, 24. 5. 1943. 


\section{1943-1945: Arzt in Auschwitz}

Das Konzentrationslager Auschwitz ${ }^{72}$ war bereits im Mai 1940 in einer ehemaligen polnischen Artilleriekaserne im oberschlesischen Oświęcim eingerichtet worden zunächst für politische Häftlinge überwiegend polnischer Nationalität. Für die Deutschen machte dieses kleine, 30 Kilometer südlich von Katowice (Kattowitz) gelegene Städtchen neben der leerstehenden Kaserne vor allem seine günstige Lage an einem wichtigen Eisenbahnknotenpunkt interessant; hier kreuzten sich die Bahnlinien nach Berlin, Warschau, Prag, Wien und Krakau. Zunächst sollte das Lager eine Gesamtkapazität von insgesamt 10000 Häftlingen erreichen und vor allem als Durchgangslager dienen, dessen Insassen in eines der KL auf dem Reichsgebiet weiterverschickt werden sollten. Die SS-Führung änderte jedoch die Planungen und bestimmte Auschwitz nunmehr zum zentralen KL für das besetzte Polen und einige weitere besetzte Gebiete, und bald war das Lager, dessen Ausbau mit der immer weiter wachsenden Zahl der Häftlinge nicht annähernd Schritt halten konnte, hoffnungslos überbelegt. Von entscheidender Bedeutung für die weitere Entwicklung des KL Auschwitz war ein Besuch Heinrich Himmlers am 1. März 1941: Der Reichsführer SS befahl, die Kapazität des Stammlagers auf 30000 Häftlinge zu erweitern. Zusätzlich sollte auf dem Gebiet des nahegelegenen Dörfchens Brzezinka unter der Bezeichnung Auschwitz-Birkenau ein weiteres Lager für 100000, später 200000 Kriegsgefangene errichtet und der IG Farben 10000 Häftlinge zur Zwangsarbeit für den Bau einer Fabrik in Monowice (Monowitz) zur Verfügung gestellt werden. Damit gliederte sich der Konzentrationslagerkomplex Auschwitz in drei große Einzellager: das Stammlager Auschwitz, das Lager Auschwitz-Birkenau, das sich in die drei Bauabschnitte BI, BII und BIII und zudem in verschiedene Lagerabschnitte gliederte, sowie das Lager Auschwitz-Monowitz. ${ }^{73}$ Im November 1943 kam es zu einem Revirement an der Lagerspitze und zu einer organisatorischen Neugliederung des Lagerkomplexes. Kommandant Höß wurde durch SSObersturmbannführer Liebehenschel abgelöst; dieser blieb als SS-Standortältester Kommandant des Gesamtkomplexes, die Lager wurden jedoch organisatorisch getrennt und erhielten nun eigene Kommandanturen: Auschwitz I (Stammlager), Auschwitz II (Birkenau) und Auschwitz III (Außenlager), zu dem neben Monowitz die rund 40 Außenlager und -kommandos gehörten. ${ }^{74}$

Wie bereits erwähnt war Auschwitz zunächst als KL für polnische Häftlinge errichtet worden, um für die Polizei in Schlesien Internierungskapazitäten zu schaffen. ${ }^{75}$ Dementsprechend stellten die Polen auch bis Mitte 1942 zunächst die einzige, dann die größte Häftlingsgruppe. Nach dem deutschen Überfall auf die Sowjetunion am 22. Juni 1941 gelangten immer mehr sowjetische Kriegsgefangene in das Lager. Die ersten Massenmorde unter Anwendung des Schädlingsbekämpfungsmit-

72 Zum Konzentrationslager Auschwitz vgl. Dlugoborski/Piper, Auschwitz; Frei u. a., Darstellungen, und Czech, Kalendarium.

73 Vgl. Piper, Entstehungsgeschichte; Strzelecka/Setkiewicz, Bau, S. 73-81, und Schulte, Entstehungsgeschichte.

74 Vgl. Standortbefehle 50/43 und 53/43, in: Frei, Standort- und Kommandanturbefehle.

75 Für die folgende Darstellung der Entwicklung von Auschwitz zum Zentrum des Mordes an den europäischen Juden vgl. Pohl, Holocaust, S. 155-159; Benz, Holocaust, S. 103 f.; Langbein, Menschen, S. 34-40; Piper, Aufgaben, S. 157-163. 
tels Zyklon B fanden in Auschwitz Anfang September 1941 in provisorisch abgedichteten Arrestzellen im Keller von Block 11 im Stammlager Auschwitz statt. Die ersten Opfer waren überwiegend kranke und entkräftete Rotarmisten, nicht mehr arbeitsfähige Häftlinge also, die auch zuvor im Rahmen der Aktion $14 \mathrm{f} 13$ schon aussortiert, in die Vernichtungsanstalten der mittlerweile abgebrochenen Euthanasie-Aktion (Aktion T4) deportiert und dort ermordet worden waren. ${ }^{76} \mathrm{Nach}$ einem ersten Versuch, der offenbar zur Zufriedenheit der Lagerführung verlaufen war, wurde in der ursprünglichen Leichenhalle des Krematoriums I eine permanente Gaskammer eingerichtet, in der immer wieder als nicht mehr arbeitsfähig eingestufte Häftlinge ermordet wurden, wiederum vor allem sowjetische Kriegsgefangene. Mittlerweile war das Lager Auschwitz-Birkenau in Betrieb genommen worden, und im Januar 1942 wurde auch hier in einem etwas abseits gelegenen Bauernhaus eine Gaskammer („Bunker $1^{\text {“) }}$ eingerichtet; im Juni wurde ein zweites Bauernhaus umgebaut („Bunker 2“).

Ursprünglich hatte Himmler in Birkenau 200000 sowjetische Kriegsgefangene als Zwangsarbeiter internieren wollen, doch die Zehntausende seit Juni 1941 dort festgehaltenen Rotarmisten starben innerhalb kürzester Zeit. Statt dessen wurden seit dem Frühjahr 1942 erste Transporte europäischer Juden in das Lager geleitet. Noch war jedoch nicht klar, daß Auschwitz zum Zentrum der Vernichtung der europäischen Juden werden sollte. Zwar hatte seit dem Sommer/Herbst $1941 \mathrm{im}$ besetzten Osteuropa der Massenmord an den Juden begonnen ${ }^{77}$ und bis Mitte 1942 hatten sich die regionalen Vernichtungsprogramme „zu einem Gesamtprogramm zur systematischen Ermordung der Juden unter deutscher Herrschaft" ausgeweitet $^{78}$, doch die Vernichtung fand bisher fast ausschließlich in Chelmo (Kulmhof), den Lagern der Aktion Reinhard (Belzec, Sobibór und Treblinka) und auf dem besetzten sowjetischen Gebiet statt. Seit Januar 1942 gab es erste, rein jüdische Transporte aus Oberschlesien, die im „Bunker 1“ ermordet wurden; ab dem 26. März rollten regelmäßig die Deportationszüge des Reichssicherheitshauptamtes (RSHA) aus dem gesamten besetzten Europa nach Auschwitz, zunächst vor allem aus der Slowakei und aus Frankreich. Die erste Selektion an der berüchtigten Rampe fand am 4. Juli statt. Knapp zwei Wochen später, am 17. Juli, besuchte Himmler das La-

76 Vgl. zur Bedeutung der während der Euthanasie-Aktion gesammelten Massenmord-Erfahrungen für die spätere Durchführung der Endlösung Friedlander, Weg.

77 So etwa im besetzten Polen (wo im annektierten Warthegau das erste nationalsozialistische Vernichtungslager Kulmhof, poln. Chelmo, Anfang Dezember seine Mordtätigkeit aufnahm), in der Sowjetunion (wo neben den Massenmorden der Einsatzgruppen etwa in der Vernichtungsstätte Maly Trostenez bei Minsk die Opfer in Gaswagen getötet wurden) und in Serbien. Vgl. den Überblick bei Longerich, der gleichzeitig betont, daß „im Herbst 1941 noch nicht die Entscheidung zur unmittelbaren Ermordung aller europäischen Juden gefallen war". Noch sei zwar der „Mord von Hunderttausenden, aber nicht von Millionen“"vorbereitet worden. Longerich, Politik, 441-465, Zitat S. 457.

78 Ein schriftlicher Befehl Hitlers zur Ermordung der europäischen Juden ist bisher nicht aufgefunden worden, und es scheint fraglich, ob es ein solches Dokument jemals gegeben hat. Zur Diskussion dieser Frage und des Problems der Datierung einer eventuellen Entscheidung Hitlers vgl. Longerich, Politik, S. 419-532 und 579-586, Zitat S. 476.

$\mathrm{Da}$ als Argument für eine letztgültige Entscheidung Hitlers bereits im Sommer 1941 regelmäßig auch auf die autobiographischen Aufzeichnungen von Rudolf Höß hingewiesen wird (vgl. Höß, Kommandant, S. 124 und 157), sei an dieser Stelle auch auf die Entgegnung Karin Orths verwiesen: Orth, Höß. 
ger und ließ sich den Ablauf der Vernichtung demonstrieren. Vermutlich erst jetzt fiel die Entscheidung, Auschwitz zum Mordzentrum auszubauen. Im Herbst wurden die Planungen für zwei neue, große Krematorien geändert und die ursprünglich als Leichenkeller vorgesehenen Räume in Gaskammern umgewandelt. Die Krematorien und Gaskammern II und III wurden im Frühjahr 1943 fertiggestellt, wenig später wurden zwei weitere (IV und V) in Betrieb genommen. ${ }^{79}$ Als Josef Mengele Ende Mai 1943 nach Auschwitz kam, war es damit nicht nur zum größten nationalsozialistischen Konzentrationslager überhaupt geworden, sondern auch zum Zentrum der Vernichtung der europäischen Juden. Die neueste Forschung geht von einer Gesamtzahl von rund 1,1 Millionen zumeist jüdischen Opfern in Auschwitz aus. 80

Über 400000 Menschen wurden in das Lager aufgenommen, als Häftlinge registriert und mit der berüchtigten Tätowierung der Häftlingsnummer am linken Unterarm versehen; die überwiegende Mehrzahl der nach Auschwitz deportierten Menschen, 75 bis 80 Prozent, wurde jedoch unmittelbar nach der Ankunft an der Eisenbahnrampe zur Ermordung selektiert und direkt in die Gaskammern geschickt; sie erscheinen in keiner Häftlingsstatistik. Sie wurden unmittelbar von der Rampe in die Krematorien II und III geführt, wo sie sich in einem unterirdischen Ankleideraum, über dessen Tür ein Schild mit der Aufschrift „Zum Baden und Desinfektion" zu sehen war, entkleiden mußten. Anschließend wurden sie über einen Korridor in die Gaskammer geführt, die als Brausebad getarnt war. „Wenn gegen die Widerspenstigen unter Einsatz von Schlägen und Hunden vorgegangen wurde, dann konnten ungefähr 2000 Männer, Frauen und Kinder in die Gaskammer gedrängt werden. Nachdem die Gaskammer voll war [...], wurde die Tür geschlossen und verriegelt [...]; auf Anweisung des beaufsichtigenden SS-Arztes [darunter auch regelmäßig Josef Mengele] öffneten dann SS-Desinfektoren [...] die Büchsen mit Zyklon B und schütteten ihren Inhalt durch die Einwurfsäulen in die Gaskammern. Im Verlauf von einigen Minuten, längstens in einem Zeitraum zwischen zehn und zwanzig Minuten, trat in Folge der Vergiftung durch das Gas der Tod der Menschen ein." ${ }^{81}$

Mengele war während seiner Zeit im Lager nicht der Arzt von Auschwitz - er war einer unter vielen. Aleksander Lasik listet in seiner Übersicht zum medizinischen Personal nicht weniger als 30 SS-Ärzte auf, die hier ihren Dienst versahen. Er war auch nicht, wie zuweilen behauptet, der (dazu noch angeblich von Himmler persönlich ernannte) ranghöchste Arzt des Lagerkomplexes. Dies war als SS-Standortarzt seit dem 1. September 1942 der SS-Hauptsturmführer Eduard Wirths, der als Chef der Abteilung V der Kommandantur für sämtliche medizinische Belange des Lagerkomplexes zuständig war. ${ }^{82}$ Dazu zählten die Bereiche Zahnmedizin, Allgemeine Medizin und Pharmazie, jeweils getrennt nach medizinischer Versorgung für die SS-Angehörigen (durch die SS-Truppenärzte) und die Häftlinge (durch die Lagerärzte). In Auschwitz-Birkenau, das sich in verschiedene Lagerabschnitte glie-

79 Vgl. zur Baugeschichte der Krematorien Pressac, Krematorien.

80 Vgl. den Forschungsüberblick bei: Piper, Zahl.

81 Pipcr, Vernichtungsmethoden.

82 Vgl. Lasik, Organisationsstruktur, S. 280-297. Die administrative Gliederung der Kommandantur war in allen Konzentrationslagern gleich. Vgl. Orth, System, S. 39-46. 
derte, gab es mehrere Leitende Lagerärzte, die für einen jeweils eigenen Lagerabschnitt zuständig waren, zum Teil aber auch in den Ambulatorien anderer Lagerabschnitte Dienst taten. Josef Mengele, nach seiner Ankunft Leitender Lagerarzt für das Zigeunerlager (Lagerabschnitt BIIe), war also zunächst auch nicht der leitende Arzt von Auschwitz-Birkenau; dies änderte sich erst, als er nach der Liquidation des Zigeunerlagers die Leitung des Häftlingskrankenbaulagers BIIf übernahm. Damit vermutlich automatisch verbunden war seit der administrativ-organisatorischen Aufspaltung des Gesamtlagerkomplexes Auschwitz im November 1943 die Stellung des 1. Lagerarztes des KL Auschwitz II (Birkenau). Nach wie vor war er allerdings dem SS-Standortarzt Eduard Wirths unterstellt. 83

Das Aufgabengebiet, das ihn als Lagerarzt in Auschwitz erwartete, hatte mit der von einem Arzt eigentlich zu erwartenden Tätigkeit - einer zumindest ansatzweisen medizinischen Grundversorgung - wenig zu tun. ${ }^{84}$ Formell waren die Lagerärzte zwar für die medizinische Betreuung der Häftlinge und für Lagerhygiene und Seuchenfragen zuständig, tatsächlich waren sie jedoch vor allem in den Vernichtungsprozeß eingebunden, der letztlich der Hauptzweck von Auschwitz war. Sie beaufsichtigten die Vergasungen, Hinrichtungen und Prügelstrafen, führten Selektionen an der Rampe und im Lager durch, töteten durch Phenolinjektionen ins Herz (das sogenannte "Abspritzen“ der Häftlinge) und stellten falsche Totenscheine aus - teils noch zu Lebzeiten des Opfers. Der Zweck des Häftlingskrankenbaus (im Lagerjargon auch „Revier“ genannt) war in Auschwitz ein doppelter: Einerseits sollten solche Häftlinge, die nur an leichtesten Erkrankungen litten, schnellstmöglich wiederhergestellt werden, um ihre Arbeitskraft zu erhalten. Deshalb erlaubte das WVHA im Frühjahr 1942, zu diesem Zwecke Lagerinsassen mit medizinischer Qualifikation in den Revieren als Häftlingsärzte einzusetzen. Diese waren es, die sich teils aufopferungsvoll um ihre Mithäftlinge kümmerten - doch waren ihre Möglichkeiten aufgrund der Tatsache, daß Sie keine Geräte oder Medikamente, ja nicht einmal ausreichende Nahrung oder angemessene hygienische Verhältnisse vorfanden, sehr begrenzt. Die Häftlinge andererseits, die an einer schwereren Verletzung, Erkrankung oder gar einer ansteckenden Seuchenkrankheit litten, konnten nicht auf Heilung hoffen. Seit Mitte 1941 führten die SS-Ärzte auch in den Krankenbauten Selektionen durch - wessen Prognose nicht binnen kürzester Zeit Heilung versprach, wurde in die Gaskammer geschickt oder mittels Phenolspritze getötet. Für diese Häftlinge war das Revier kein Ort der Heilung, sondern der Vernichtung: „Es gab mehrfach Besprechungen aller in Auschwitz tätigen Ärzte“, erklärte einer dieser Mediziner später vor Gericht, um „feste Kriterien zu den Selektionen herauszuarbeiten. [Danach] ergaben sich im wesentlichen folgende Merkmale [...]: Das waren Hungerödeme, das völlige Fehlen von Fettgeweben in den Gesäßbacken (um das festzustellen, ließen die SS-Ärzte die nackt angetretenen Häftlinge sich umdrehen), der Verdacht auf eine Tbc, eine tatsächliche Tbc war wegen der fehlenden medizinischen Geräte schwer festzustellen [...], Unfälle mit Knochenbrüchen und schwere Eiterungen [...]. Über die Tatsache, daß diese Häft-

83 Vgl. Lasik, Organisationsstruktur, S. 289-293; Kubica, Mengele, S. 377 f.; Zofka, KZ-Arzt, S. 255.

84 Zur Tätigkeit der Lagerärzte vgl. Lasik, Organisationsstruktur, S. 289-293; Strzelecka, Häftlingsspitäler; Czech, Rolle. 
linge getötet wurden, haben wir uns kaum unterhalten. Ich persönlich sah darin auch gewissermaßen die Erfüllung eines der Zwecke, die das Lager Auschwitz hatte." 85

Seit Februar 1943 wurden auch Sinti und Roma in großem Umfang nach Auschwitz deportiert. Dort wurden sie in Birkenau im Zigeuner-Familienlager (Lagerabschnitt BIIe) untergebracht. ${ }^{86}$ Zuständiger Lagerarzt war zunächst der SS-Arzt Dr. Benno Adolph, der jedoch Ende April an Scharlach erkrankte und bis November dienstunfähig wurde. ${ }^{87}$ Sein Nachfolger war Josef Mengele. Die Zigeuner hatten in Auschwitz zunächst eine Art Sonderstatus: Die Familien wurden nicht getrennt (deshalb die Bezeichnung Familienlager), sie durften ihre Habe vorerst behalten und mußten keine Häftlingskleidung tragen. Ebensowenig wurden sie zur industriellen Zwangsarbeit herangezogen. Trotz dieser Vergünstigungen waren die Verhältnisse auch im Zigeunerlager fürchterlich: In die 26 Baracken wurden allein bis Ende März 1943 über 12000 Menschen gepfercht, insgesamt durchliefen das Lager laut Hauptbuch bis zum 31. Juli 1944, zwei Tage vor der endgültigen Auflösung des Lagers, fast 21000 Insassen.

Die hygienischen Zustände waren katastrophal, es grassierten Infektionskrankheiten und Mitte Mai brach eine Flecktyphusepidemie (auch Fleckfieber genannt) aus. Fünf Tage vor Mengeles Ankunft, am 25. Mai 1943, wurden rund $1000 \mathrm{krank}$ heitsverdächtige Zigeuner in die Gaskammern geschickt ${ }^{88}$; der Krankenbau wurde schrittweise von zunächst zwei Baracken ( 30 und 32) auf zuletzt sechs Baracken (zusätzlich 22, 24, 26, 28) erweitert. Die Revierbaracken entsprachen in ihrer Bauweise und Ausstattung den anderen Baracken des Lagers. Sie waren rund vierzig Meter lang und neun Meter breit und hatten an Stelle von Fenstern ein schmales Oberlicht. Nach vorne lagen abgetrennt einige Diensträume (Blockleiter, Häftlingsarzt, Schreibstube) und nach hinten eine Küche, ein Waschraum, eine Latrine und eine Leichenkammer. Ausgestattet war das Revier mit den üblichen, 2,80 mal 1,85 Meter großen dreistöckigen Holzpritschen, die je nach Bedarf mit vier bis acht Patienten pro Etage belegt wurden. Matratzen gab es natürlich nicht, die Kranken lagen ohne Laken auf Strohsäcken und als Decke diente, was gerade greifbar war.

85 Aussage Dr. Horst Fischers, zit. nach Langbein, Menschen, S. 536. Dieses Vorgehen führte dazu, daß Tuberkulosekranke, umgehend in die Gaskammern geschickt wurden, sich nicht mehr im Revier meldeten, ihre Mithäftlinge ansteckten und die Zahl der Toten sprunghaft anstieg

86 Zum Zigeunerlager in Auschwitz-Birkenau vgl. Dlugoborski, Sinti; Zimmermann, Rassenutopie, S. 316-344; Luchterhandt, Weg, S. 272-306; Parcer, Gedenkbuch. Vgl. außerdem die Darstellung bei Völklein, Mengele, S. 111-125, die auf den Zeugenaussagen der polnischen Funktionshäftlinge Tadeusz Snieszko, Tadeusz Szymanski und Danuta Szymanska beruht. Diese waren bis zur dessen Auflösung als Schreiber im Zigeunerlager tätig und veröffentlichten ihre Erinnerungen 1965 in der Krakauer Ärztlichen Umschau. Eine deutsche Übersetzung findet sich in den Akten der Frankfurter Staatsanwaltschaft (Sta F/M, Az 4 Js 340/68, Erm.A., Bd. XIX, Bl. 76-101).

87 Völklein, Mengele, S. 92.

88 Die Fleckfieber-Aktion im Zigeunerlager wird häufig fälschlich Mengele zugeschrieben, der aber erst am 30. Mai 1943 seinen Dienst in Auschwitz antrat. Dieser Fehler dürfte auf den Haftbefehl von 1981 zurückgehen (Sta F/M, Az 4 Js, 340/68, Fahnd.A., Haftbefehl der 22. Strafkammer des Landgerichts Frankfurt am Main gegen Josef Mengele, 19. 1. 1981, S. 16f.), dem auch Posner/Ware, Mengele, S. 44, vertrauen. 
Bald nach seiner Ankunft sorgte Mengele für eine Neuerung im Zigeunerlager, die ihm anfänglich große Zuneigung und das Vertrauen der Insassen einbrachte. Er ließ in den Baracken 29 und 31 einen „Kindergarten“ einrichten, in dem alle Kinder im Alter bis zu sechs Jahren untergebracht und von mehreren Häftlingsfrauen betreut wurden. Die Kinder erhielten zusätzliche Verpflegung (zeitweise sogar Milch, Butter, Fleischbrühe, sogar Schokolade oder Konfitüre, allerdings immer abhängig davon, was die ausgebenden SS-Männer und die Funktionshäftlinge übrig ließen) und es wurde sogar ein Kinderspielplatz mit Sandkasten und Schaukel eingerichtet. Doch die Sinti und Roma begriffen bald, daß dies hauptsächlich Propagandazwekken diente, als immer wieder hochrangige SS-Männer und Zivilisten erschienen, um die Kinder zu fotografieren und zu filmen. Ohnehin war dies nur die halbe Wahrheit, denn Mengele nutzte den Kindergarten vor allem als Rekrutierungsreservoir für seine Versuche. Hier waren unter anderem die ersten Zwillingspärchen untergebracht, die er für seine Forschung mißbrauchte.

Mangelernährung und Seuchen dezimierten die Häftlinge schnell. Schon im ersten Halbjahr seines Bestehens starben im Zigeunerlager rund 7000 Menschen, und am 1. Juni 1944 waren von den fast 21000 bis dahin dort registrierten Häftlingen weit über zwei Drittel bereits tot. Von den noch Lebenden wurden am 15. April 19441357 arbeitsfähige Frauen und Männer in die KL Ravensbrück und Buchenwald deportiert. Am Abend des 2. August 1944 führte Mengele unter den noch im Lager verbliebenen Sinti und Roma eine weitere Selektion durch - die Liquidierung des Lagers war für diese Nacht vorgesehen. ${ }^{89}$ Nochmals wählte Mengele 1408 Frauen und Männer, die ebenfalls in die beiden genannten KL verbracht wurden. Die nun im Zigeunerlager noch übrigen 2897 Menschen, vor allem Kinder, Kranke, Schwache und Alte, wurden noch am gleichen Abend in den Gaskammern des Krematoriums V ermordet. Nicht einmal die Zwillinge wurden verschont: Obwohl Mengele offenbar bis zuletzt versucht hatte, sein „Forschungsmaterial“ zu retten, war ihm eine Verlegung verwehrt worden; um wenigstens noch einen letzten Nutzen aus ihrem Tod ziehen zu können, erschoß er eigenhändig die noch lebenden 24 Zwillingsgeschwister im Vorraum des Krematoriums und ordnete die Sektion der Leichen an.

Erfahrungen mit der Liquidation eines ganzen Lagerabschnitts hatte Mengele schon wenige Wochen zuvor gesammelt, als Mitte Juli das Familienlager für Juden aus Theresienstadt (BIIb) ${ }^{90}$ aufgelöst wurde. Der Ablauf war dabei ähnlich gewesen: Nachdem bereits im März 3791 Männer, Frauen und Kinder in den Gaskammern der Krematorien II und III ermordet worden waren, kam es Anfang Juli zu einer Selektion, bei der rund 2000 Frauen und 1000 Männer als arbeitsfähig ausgewählt und in andere Lager überstellt wurden. Die noch übrig gebliebenen etwa 4000 Juden wurden in den beiden Nächten vom 10. zum 11. und vom 11. zum 12. Juli 1944 in den Gaskammern ermordet. Ein für Mengele sicher nicht unbedeutender Unterschied zur Auflösung des Zigeunerlagers war allerdings, daß es ihm bei

89 Völklein, Mengele, S. 116-119, gibt als Datum für die Liquidierung des Lagers fälschlicherweise den 1. August 1944 an. Auch seine Angabe, mindestens 3300 Zigeuner seien an jenem Abend ermordet worden, greift zu hoch.

90 Strzelecka/Setkiewicz, Bau, S. 112-114. Vgl. außerdem: Kubica, Mengele, S. 384 und 414. 
dieser ersten großen Liquidierungsaktion gelang, seine Zwillinge zu retten und in andere Lagerabschnitte zu verlegen.

Die Ermordung der Häftlinge des Familienlagers für Juden aus Theresienstadt fand im Rahmen der Maßnahmen gegen eine grassierende Flecktyphusepidemie statt, die Mengele als Spezialist für Seuchenbekämpfung geleitet zu haben scheint. Als solcher hatte er sich offenbar mittlerweile einen Namen gemacht, und seine „innovativen“ Strategien fanden den Beifall seines Vorgesetzten: Der Standortarzt Wirths nannte im Februar 1944 als einen von mehreren Gründen für eine Verleihung des Kriegsverdienstkreuzes an Mengele seine Erfolge bei der Bekämpfung einer Typhusepidemie im Frauenlager, die Ende 1943 ausgebrochen war. Das Frauenlager stand zu diesem Zeitpunkt unter Aufsicht Mengeles, und die ehemalige Häftlingsärztin Ella Lingens beschreibt seine Strategie: „Er schickte einen ganzen jüdischen Block mit 600 Frauen in die Gaskammer und machte den Block frei. Dann ließ er ihn von oben bis unten desinfizieren. Er stellte dann Badewannen zwischen diesem und dem nächsten Block auf, und die Frauen aus dem nächsten Block traten heraus, sie wurden desinfiziert und in den sauberen Block verlegt. [...] Genauso wurde der nächste Block gesäubert und so weiter, bis alle Blocks desinfiziert waren. "91 Mengele entwickelte noch weitere Methoden zur "Seuchenbekämpfung“. Um die oben bereits erwähnte Fleckfieberepidemie im Zigeunerlager einzudämmen, ordnete er zur Bekämpfung des Überträgers großangelegte Entlausungsaktionen an, die vor allem während der Wintermonate viele Opfer forderten. Die Häftlinge mußten ihre Baracken verlassen und sich ausziehen. Sie wurden entlaust und desinfiziert und mußten anschließend - egal bei welcher Witterung - nackt im Freien ausharren, bis auch ihre Kleidung und die Baracken gereinigt waren. Zur Bekämpfung der Krätze, der in Birkenau wohl am weitesten verbreiteten Krankheit, entschied sich Mengele im Frühjahr 1944 für eine ähnliche, nicht minder menschenverachtende und lebensgefährliche Kur: Es wurden zwei Behälter mit einer gerade noch verträglichen Lösung aus Natriumschwefelsäure bzw. Salzsäure aufgestellt. Um die Entzündungsherde zu desinfizieren und die Milben abzutöten, mußten die Häftlinge in beide Behälter steigen; wer die Säure überstand, mußte auch hier anschließend nackt im Freien auf seine Kleider warten, die ebenfalls einer Reinigung unterzogen wurden. ${ }^{92}$

Der oben erwähnte Vorschlag zur Ordensverleihung von Standortarzt Wirths war übrigens von Erfolg gekrönt: Aus einer dienstlichen Beurteilung Josef Mengeles, die ebenfalls aus der Feder Wirths' stammt, geht hervor, daß ihm nicht zuletzt für seine Erfolge bei der SS-spezifischen Seuchenbekämpfung das Kriegsverdienstkreuz II. Klasse mit Schwertern verliehen wurde. ${ }^{93}$ Diese Beurteilung stammt vom 19. August 1944, datiert also knapp zwei Wochen nach der Auflösung des Zigeunerlagers. SS-Hauptsturmführer Wirths lobte darin seinen der bisherigen Aufgabe ledigen Untergebenen Mengele in den höchsten Tönen: „Seine Leistungen“ seien „als hervorragend zu bezeichnen“, und er erscheine „für jede anderweitige Verwendung und auch für die nächsthöhere Verwendung durchaus geeignet “94. Tatsächlich über-

91 Zit. nach Posner/Ware, Mengele, S. 45. Vgl. auch Kubica, Mengele, S. $413 \mathrm{f}$.

92 Vgl. Völklein, Mengele, S. 116-118.

93 BAB, BDC, Mengele, Beurteilung von Dr. Josef Mengele, 19. 8. 1944.

94 Ebenda. 
nahm Mengele wenig später das Häftlingskrankenbaulager BIIf und avancierte zum 1. Lagerarzt von Auschwitz II (Birkenau).

Mengele machte sich also in besonderer - besonders menschenverachtender Weise um die „Hygiene“ des Lagers verdient. Auch andere Aufgaben, die ihm als Lagerarzt zufielen, erledigte er ohne erkennbare Skrupel und mit großer Pedanterie. Dies galt etwa für die Selektionen, die die Ärzte sowohl an der Rampe als auch immer wieder im Lager selbst durchzuführen hatten. Zeugenaussagen zu Lagerselektionen Mengeles sind für alle Lagerabschnitte in großer Zahl überliefert. Der Lagerälteste im Quarantänelager (BIIa), Hermann Diamanski, schilderte den Ablauf einer solchen Selektion: „Die Häftlinge mußten antreten und blockweise Aufstellung nehmen. Dr. Mengele ging von Block zu Block“ und „deutete auf diejenigen, welche er für die Vergasung vorgesehen hatte. Ein ihm folgender SS-Mann schrieb die Häftlingsnummern auf" ${ }^{95}$ Danach bekam Diamanski eine Liste der notierten Häftlinge, die er „dann in einen Block legen“ mußte. „Am gleichen Tag wurden sie mittels Lastkraftwagen dann zur Vergasung gefahren." Dies galt aber nur, wenn Mengele eine genügend große Zahl selektiert hatte: „Hatte Dr. Mengele nur vierzig bis fünfzig Personen ausgesucht, so wurden diese durch Genickschuß ums Leben gebracht." Wenn es galt, Kinder zu selektieren, griff Mengele zu einer besonderen Methode, die Diamanski in seiner Aussage ebenfalls beschreibt: „Dr. Mengele ließ einen circa 1,20 bis $1,40 \mathrm{~m}$ hohen Rahmen aufstellen. Wer nun ohne anzustoßen [...] hindurchgehen konnte, war zur Vernichtung bestimmt." Einmal versteckte Diamanski zwei dieser Kinder im Lager - sie wurden entdeckt und Mengele "machte Meldung. Ich bekam dafür als Strafe fünfzig Stockhiebe, und die Kinder wurden ebenfalls ums Leben gebracht."

Zuweilen fand Mengele jedoch nicht die Zeit, Lagerselektionen persönlich durchzuführen. Dann übertrug er die furchtbare Aufgabe, die Mithäftlinge in den Tod zu schicken, an einen der Häftlingsärzte. Manche fanden den Mut, sich dem zu entziehen. ${ }^{96}$ In den Krankenbauten entschied sich Mengele ebenfalls von Zeit zu Zeit für eine indirekte Form der Selektion, bei der er sich nicht einmal die Mühe machte, die Menschen, die er für den Tod in der Gaskammer auswählte, persönlich in Augenschein zu nehmen. Anhand der Krankenakten, die immer mit äußerster Sorgfalt geführt und alle drei Tage aktualisiert werden mußten, wählte Mengele seine Opferer entschicd über Leben und Tod der Häftlinge nach Aktenlage, und die Schreiber im Krankenbau erkannten anhand der fehlenden Karteikarten, wer für die Gaskammer vorgesehen war. Zuweilen machte Mengele sich aber nicht einmal die Mühe, sich mit den Krankenakten selbst zu befassen: Er ließ sich von den Häftlingsärzten eine Liste der Kranken mit Diagnose und Prognose aushändigen. War eine zu lange Heilungsdauer angegeben, war dies das Todesurteil für den Betreffenden. Die Häftlingsärzte, die um diesen Zusammenhang wußten, gaben oft einen kurzen Zeitraum an oder schrieben Kranke arbeitsfähig, um ihr Leben zu retten, doch dann mußten diese ungeachtet ihres oft desolaten Zustandes aus dem Revier entlassen werden was meist ebenfalls einem Todesurteil gleichkam. ${ }^{97}$

${ }^{95}$ F/M, Az 4 Js 340/68, Erm.A., Bd. I, Bl. 147-149, Aussage von Hermann Diamanski, 12. 2. 1959.

96 Vgl. Völklein, Mengele, S. $134 \mathrm{f}$.

97 Vgl. ebenda, S. $140 \mathrm{f}$. 
Wie alle Ärzte in Auschwitz hatte Mengele neben seinem Dienst im Lager auch noch „Rampendienst“ zu tun, das heißt, er hatte bei ankommenden Transporten die Deportierten in Arbeitsfähige und nicht Arbeitsfähige zu scheiden. Erstere wurden ins Lager aufgenommen und erhielten so eine letzte Gnadenfrist, während letztere direkt in die Gaskammern geführt wurden. In den Ermittlungsakten der Frankfurter Staatsanwaltschaft findet sich eine Vielzahl von Zeugenaussagen, die Rampenselektionen beschreiben, bei denen Mengele tätig war. ${ }^{98}$ Diese Selektionen liefen nicht immer gleich ab: Mal ließ Mengele die Kolonne der Häftlinge an sich vorbeimarschieren, mal ging der SS-Arzt selbst durch die Reihen und entschied dann nach einem kurzen prüfenden Blick, oft aus einigen Metern Entfernung, immer ohne eingehende Begutachtung oder gar medizinische Untersuchung, über das weitere Schicksal der ihm Ausgelieferten. Dies geschah entweder durch eine lässige Handbewegung, durch einen Schlag mit einem Stock, einen nach links oder rechts gestreckten Daumen oder schlicht durch die Worte „rechts“ oder „links“, wobei rechts das vorläufige Überleben (die Lebenserwartung betrug im Lager durchschnittlich etwa drei Monate), links den sofortigen Tod bedeutete; von Zeit zu Zeit pfiff der immer akkurat gekleidete, bisweilen lächelnde Mengele wohl auch eine Opernarie, während er über Leben und Tod seines Gegenübers entschied. Überhaupt scheint Mengele die Tätigkeit an der Rampe nicht belastet zu haben: Einige der Ärzte in Auschwitz „mußten sich erst betrinken, ehe sie an der Rampe erschienen“, berichtet die Häftlingsärztin Ella Lingens, und es habe nur zwei gegeben, die "die Selektionen ohne jegliche Aufputschmittel"99 vorgenommen hätten: Einer davon war Josef Mengele. „Er drängte sich förmlich danach, teilzunehmen"100, so Ludwig Wörl, Lagerältester im Krankenbau von Auschwitz I. Sogar außerhalb seiner Dienstzeiten hielt er sich dort auf, denn ihn trieb die Hoffnung, in den neu ankommenden Transporten „Material“ für seine Experimente zu finden; er fürchtete, es könnte ihm entgehen, wenn er nicht selbst an der Rampe stand.

Für diese grausamen, pseudo-wissenschaftlichen Experimente, die Josef Mengele während seiner Zeit als Lagerarzt an den Häftlingen durchführte und für die er an der Rampe Opfer suchte, steht sein Name heute hauptsächlich. Menschenversuche waren in den nationalsozialistischen Konzentrationslagern nichts Außergewöhnliches. ${ }^{101}$ Initiatoren eines Teils dieser Experimente waren Himmler persönlich, der

98 Vgl. die Auswahl von Zeugenaussagen bei Völklein, Mengele, S. 128-133. Vgl. außerdem Posner/Ware, Mengele, S. $46 \mathrm{f}$.

99 Zit. nach: Posner/Ware, Mengele, S. 46.

100 Zit. nach: Völklein, Mengele, S. 129.

101 Das KL Dachau etwa wurde als „Lehrbetrieb“ für die SS-Akademie Graz genutzt und angehende SS-Ärzte „nutzten“ die Häftlinge als Lehr- und Erprobungsmaterial; der berüchtigte Dr. Sigmund Rascher führte für die Luftwaffe Unterdruck- und Kältetodversuche durch; in den verschiedensten KL wurden neue Heilmethoden, Medikamente oder Impfstoffe an Häftlingen erprobt, wofür diese natürlich erst mit Malaria, Hepatitis, Tuberkulose oder Typhus angesteckt werden mußten (z. B. in Dachau, Mauthausen, Buchenwald, Natzweiler); es wurden sog. kriegschirurgische Experimente durchgeführt, bei denen den Häftlingen Schlachtfeld-typische, schwerste Verletzungen zugefügt und diese anschließend planmäßig verunreinigt wurden, um Gasbrand zu erzeugen (z. B. in Dachau, Ravensbrück, Sachsenhausen); an Häftlingen der KL Groß-Rosen, Natzweiler, Dachau und Sachsenhausen wurden Giftgasversuche durchgeführt (mit Phosgen, Tabun und Lost); dazu kamen noch eine Vielzahl weiterer Experimentierfelder. Vgl. Klee, Auschwitz; Kopke, Menschenversuche; Ebbinghaus/Roth, Kriegswunden; Roth, Höhen; Werther, Menschenversuche. 
Reichsarzt SS Prof. Dr. med. Ernst Grawitz und Wolfram Sievers, SS-Standartenführer, Reichsgeschäftsführer des Vereins Ahnenerbe ${ }^{102}$ und Direktor des Instituts für wehrwissenschaftliche Zweckforschung der Waffen-SS. Diese zentral geplanten Experimente sollten der Kriegführung, der Bevölkerungspolitik nach dem Krieg oder der Bestätigung der eigenen Rassentheorien dienen; daneben nutzten eine ganze Reihe pharmazeutischer Firmen oder Institute die KL für Versuchsreihen neuer Medikamente oder Impfstoffe, und auch ganz private Forschungsinteressen konnten zur Förderung der wissenschaftlichen Karriere verfolgt werden.

Auch in Auschwitz nutzten eine ganze Reihe von Ärzten die grenzenlose Verfügungsgewalt über die Gefangenen, um „Forschung“ der unterschiedlichsten Art und aus unterschiedlichsten Motiven zu betreiben. ${ }^{103}$ Prof. Dr. Carl Clauberg etwa suchte nach neuen Methoden zur Massensterilisierung von Frauen und hatte von Himmler auf sein Ersuchen hin Ende 1942 die Erlaubnis erhalten, seine Experimente im KL Auschwitz durchzuführen. In Block 10 des Stammlagers spritzte er seinen weiblichen Opfern chemische Reizflüssigkeit in die Gebärmutter. Clauberg und ein weiterer SS-Arzt, Dr. Horst Schumann, suchten außerdem einen Weg, Männer und Frauen mittels Röntgenbestrahlung unfruchtbar zu machen; die Röntgenbestrahlung hatte schwerste Verbrennungen zur Folge und einem Teil der Opfer wurden später Eileiter bzw. Hoden entfernt, um die Folgen der Behandlung zu beobachten. Für diese Experimente zur Unfruchtbarmachung von Männern und Frauen scheint auch Mengele ein besonderes Interesse entwickelt zu haben. Er war mit der Praxis der Zwangssterilisation bereits während seiner Zeit als Assistent in Frankfurt als Gutachter vor Erbgesundheitsgerichten in Berührung gekommen.104 Offenbar wollte Mengele keinesfalls den Anschluß auf diesem wichtigen (und von Himmler persönlich geförderten) Gebiet verlieren, obwohl er in diesem Bereich über keinerlei Qualifikation verfügte. Er entfernte Häftlingen nacheinander erst den einen, dann den anderen Hoden, beteiligte sich an den bereits beschriebenen Röntgenbestrahlungen und entfernte Frauen die Eierstöcke - all das, wie gesagt, ohne jegliche Erfahrung etwa auf dem Gebiet der Chirurgie zu haben. ${ }^{105}$

Dr. Friedrich Entress (von dem Hermann Langbein schrieb, dieser habe für ihn „am krassesten den Typ verkörpert, der Initiative zu Fleißaufgaben ergriffen

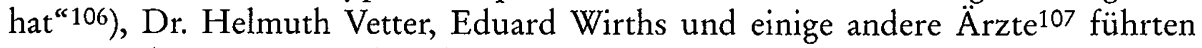
von 1941 bis 1944 Versuchsreihen durch, um an Häftlingen die Wirksamkeit neuer Medikamente zu erproben. Dies geschah überwiegend im Auftrag der IG Farben, genauer gesagt im Auftrag der zum Konzern gehörenden Firma Bayer. ${ }^{108}$ Meist

102 Vgl. Kater, Ahnenerbe.

103 Vgl. neben der oben bereits angeführten, allgemeinen Literatur zu Menschenversuchen in KL: Strzelecka, Die Experimente; Strzelecka, Medizinische Experimente im KL; Völklein, Mengele, S. 172-174.

104 Vgl. S. $86 \mathrm{ff}$.

105 Vgl. die Zeugenaussagen bei Völklein, Mengele, S. $164 \mathrm{f}$.

106 Langbein, Menschen, S. 493.

107 Dr. Fritz Klein, Dr. Werner Rohde, Dr. Hans Wilhelm König, Dr. Victor Capesius (Leiter der Lagerapotheke) und Dr. Bruno Weber (Leiter der Hygienisch-bakteriologische Untersuchungsstelle der Waffen-SS in Rajsko).

108 Irena Strzelecka zitiert aus der Korrespondenz der Firma Bayer mit der Kommandantur des KL Auschwitz: „Erhielten den Auftrag für 150 Frauen. Trotz ihres abgezehrten Zustandes 
wurden die Häftlinge zuerst mit der zu therapierenden Krankheit infiziert (darunter Typhus, Tbc, Diphtherie, Trachom oder Erysipel), dann versuchsweise mit den Versuchspharmazeutika behandelt, regelmäßig geröntgt und nach ihrem Tod (der normalerweise eintrat, da die Medikamente meist wirkungslos waren) seziert. Vetter und Entress erprobten außerdem mit ähnlichen Methoden die Wirksamkeit von Impfstoffen gegen Fleckfieber. An diesen Testreihen scheint Mengele sich nicht oder nur am Rande beteiligt zu haben; anders verhielt es sich mit der unter Lagerärzten, die über keine chirurgische Ausbildung verfügten, beliebten Praxis, an Häftlingen Eingriffe aller Art zu Fortbildungszwecken durchzuführen. Für diese Operationen lag in der Regel keinerlei medizinische Indikation vor, und sie fanden oft genug ohne Narkose statt. Neben Friedrich Entress, Horst Fischer und Heinz Thilo soll auch Josef Mengele solche Übungsoperationen durchgeführt haben auch ihm fehlte ja die chirurgische Qualifikation. Ein französischer Häftlingschirurg mußte ihm als Tutor und Assistent zur Verfügung stehen; nach den ersten Schnitten wagte sich Mengele auch an schwierigste Eingriffe: Entfernung der Gebärmutter, Magenöffnungen, Entfernung von Organen. Wer die Operation überlebte, endete in der Regel in der Gaskammer.

Jenö Fried, ein ungarischer Jude, überlebte eine solche Übungsoperation Mengeles. Es handelte sich um eine Knochenmarkstransplantation: „Der Pfleger fesselte mich an den Tisch. Dann trat Mengele und der andere im weißen Mantel an mich heran, und sie schnitten an mehreren Stellen meinen völlig gesunden rechten Unterschenkel auf. Mit einem Meißel oder einem ähnlichen Gerät schlugen sie Teile aus meinem Unterschenkelknochen heraus und zogen durch meinen Unterschenkel ein Rohr. Dieser Eingriff erfolgte ohne Anästhesie. Ich litt unter unaussprechlichen Schmerzen und fiel mehrmals in Ohnmacht. Der Pfleger drückte eine Decke auf meinen Kopf, um meine Schreie zu ersticken. Nach der Operation verband Mengele [...] meine Wunde [...], doch sie ließen das Rohr in meinem Bein. "109 Sechs Wochen lang mußte Fried alle drei bis vier Tage wieder auf den Operationstisch, jedes Mal wurde ihm - ohne Betäubung - Knochenmark aus dem Unterschenkelknochen entnommen.

Daneben gab es noch eine ganze Reihe weiterer Ärzte und Wissenschaftler, die von den in Auschwitz zur Verfügung stehenden Humanressourcen profitieren wollten. Von August bis November 1942 führte Prof. Dr. Dr. Johann Paul Kremer, der vertretungsweise nach Auschwitz kommandiert war, Forschungen zu durch Hunger verursachten Veränderungen im menschlichen Organismus durch; er wählte extrem entkräftete und ausgehungerte Häftlinge (sog. Muselmänner) aus, die in das Krankenrevier des Stammlagers aufgenommen werden wollten und tötete sie durch eine Phenolspritze, nachdem er sie - bereits auf dem Sektionstisch festgeschnallt - über Details ihrer Krankengeschichte befragt hatte. Anschließend entnahm er den noch warmen Leichen ihm interessant erscheinende Organe.

Standortarzt Wirths führte in Zusammenarbeit mit seinem Bruder, der in Hamburg als Gynäkologe praktizierte und eine wissenschaftliche Karriere anstrebte,

wurden sie als zufriedenstellend befunden. Die Versuche wurden gemacht. Alle Personen starben. Wir werden uns bezüglich einer neuen Sendung bald mit Ihnen in Verbindung setzen." (Strzelecka, Experimente im KL, S. 147).

109 Zit. nach: Völklein, Mengele, S. 172. 
Experimente zur Erforschung des Gebärmutterhalskrebses durch; nach einigen Wochen befaßte er sich allerdings nicht mehr selbst damit, sondern betraute einen Häftlingsgynäkologen mit den Versuchen. Im Spätsommer 1944 entsandte die Wehrmacht Dr. Emil Kaschub nach Auschwitz, um durch Versuchsreihen herauszufinden, welche Methoden deutsche Soldaten an der Ostfront einsetzten, um Krankheiten zu simulieren. Der Direktor des Anatomischen Instituts der Universität Straßburg, Prof. Dr. August Hirt, ließ zur Einrichtung einer anatomischen Sammlung jüdischer Skelette nach Himmlers Einwilligung durch Dr. Bruno Beger 115 Häftlinge auswählen, die anschließend in das KL Natzweiler verlegt wurden, wo sie getötet und ihre Skelette herauspräpariert wurden. Für Dr. Kurt Heissmeyer, der sich mit Tbc befaßte, wurden 20 jüdische Kinder noch im Dezember 1944 ins KL Neuengamme verlegt; um die Menschenversuche zu vertuschen, wurden die Kinder im April 1945 in einer Schule am Bullenhuser Damm in Hamburg erhängt.

Wie bereits geschildert schenkte Josef Mengele der großen Mehrzahl seiner Patienten - wie seine Kollegen auch - kaum Beachtung. Dies änderte sich schlagartig, wenn ihn jemand auf einen Häftling aufmerksam machte, der in das Schema eines seiner besonderen Interessengebiete paßte. Im medizinisch-klinischen Bereich galt dies vor allem für Häftlinge, die an einer außerhalb der Lager in Europa kaum noch auftretenden Krankheit litten: Noma (oder Wasserkrebs), das als fortgeschrittene bakterielle Entzündung der Mundschleimhaut auch tiefere Gewebsschichten und Knochen befällt, große Löcher in die Wangenmuskulatur frißt und schließlich zum Tod durch Sepsis führt. Sie tritt vor allem bei Kindern und Jugendlichen auf, deren köpereigene Abwehr durch Mangelernährung extrem geschwächt ist und findet sich heute noch in den Hungerregionen der Dritten Welt. Die Betroffenen wurden in eine eigene Baracke verlegt, und Mengele ließ durch Fotografien und einen Häftling, der Kunstmaler war, den Krankheitsverlauf dokumentieren. An einigen nomakranken Häftlingen studierte Mengele den Einfluß der Ernährungssituation auf das Krankheitsbild: Nachdem sie zunächst die üblichen Lagerrationen erhalten hatten, erhielten sie Medikamente und eine Aufbaudiät. Ihr Zustand verbesserte sich, woraufhin Mengele die Aufbaudiät absetzen ließ, um die erneute Verschlechterung zu beobachten. Dies konnte sich einige Male wiederholen. Mengele soll sich bei seinen Beobachtungen jedoch nicht auf bereits Erkrankte beschränkt, sondern durch die bewußt durchgeführte Infektion Gesunder für Nachschub an Studienmaterial gesorgt haben. Die Köpfe einiger verstobener Kinder schickte Mengele an das Hygiene-Institut der Waffen-SS in Rajsko, wo histopathologische Schnitte angefertigt wurden, die zumindest teilweise für die SS-Akademie in Graz bestimmt waren.110

Doch Josef Mengeles größtes Interesse galt auch in Auschwitz dem nicht-klinischen Bereich, der ihn bereits während des Studiums fasziniert und dem er seine bisherige wissenschaftliche Karriere gewidmet hatte. ${ }^{111}$ Als promovierter Anthropologe und ausgewiesener Genetiker verfügte er über Qualifikationen, die seinen Kollegen fehlten und die, wäre die tatsächliche Aufgabe der Lagerärzte die medizinische Betreuung der Häftlinge gewesen, in Auschwitz völlig nutzlos gewesen

110 Vgl. Völklein, Mengele, S. 118f. und 160-162; Kubica, Mengele, S. 378 f. und 394 (dort das Faksimile eines entsprechenden Auftragsscheines, der wohl dem Kopf der Leiche eines zwölfjährigen Kindes beigegeben war).

111 Vgl. S. $83 \mathrm{f}$. 
wären. Unter den gegebenen Umständen aber bot sich dem Anthropologen ein einmaliges Betätigungsfeld, das Mengele zu nutzen wußte, wie sein Vorgesetzter Wirths in der bereits zitierten dienstlichen Beurteilung wohlwollend festhält: Mengele habe „eifrigst die kurze ihm verbliebene dienstfreie Zeit dazu benützt, sich selbst weiterzubilden“ und „in seiner Arbeit unter Auswertung des ihm auf Grund seiner Dienststellung zur Verfügung stehenden wissenschaftlichen Materials der anthropologischen Wissenschaft einen wertvollen Beitrag geliefert." 112 Die Realität dieser „Auswertung [...] wissenschaftlichen Materials“ war weit grausamer, als die dürren Worte Wirths' erahnen lassen.

Das besondere Interesse Mengeles galt mit der Zwillingsforschung 113 einem geradezu klassischen Gebiet der Anthropologie und der Genetik. Sein Mentor von Verschuer hatte sich in der Zwillingsforschung einen Namen gemacht, und der Leiter des Berliner Kaiser-Wilhelm-Institutes für Anthropologie interessierte sich für die Forschungen seines Protegés, mit dem er in regem Briefwechsel stand und der ihn immer wieder in Berlin besuchte. Mengele muß sofort klar gewesen sein, welch großartige Möglichkeiten sich ihm in Auschwitz boten: Hunderte Zwillingspärchen, vor allem Kinder, standen ihm zur freien Verfügung und hatten keinerlei Möglichkeit, sich zu entziehen. Auch waren hier seiner Forscherphantasie, anders als früheren, „zivilen“ Forschern, keinerlei Grenzen gesetzt hinsichtlich der Art der Untersuchungen und Experimente. Hier bot sich ihm die einmalige Chance, die empirische Grundlage für Jahre, wenn nicht Jahrzehnte der wissenschaftlichen Arbeit und einer großen Universitätskarriere zu legen, und Mengele war entschlossen, sie zu nutzen.

Seine Opfer fand Mengele zunächst im Zigeunerlager (BIIe) und im Familienlager für Juden aus Theresienstadt (BIIb). Später bemühte er sich vor allem, der Zwillinge bereits während der Selektion an der Rampe habhaft zu werden. Mengeles Zwillinge genossen innerhalb des Lagers einen Sonderstatus. Nachdem sie von ihren Eltern (die, wie die Kinder bald erfahren mußten, meist direkt in die Gaskammern geschickt wurden) getrennt worden waren, wurden ihnen bei der Aufnahme nicht, wie sonst üblich, die Haare geschoren und sie durften ihre eigene Kleidung behalten. Sie wurden abgesondert in einer der Krankenbaubaracken des jeweiligen Lagerabschnittes untergebracht, nach der Liquidierung des Zigeunerlagers und des Familienlagers für Juden aus Theresienstadt waren dies vor allem die Baracke 22, seit Juli 1944 Baracke 1 des Krankenreviers im Frauenlager BIa und Block 15 im Männerkrankenbaulager (BIIf). Die Wohnverhältnisse waren ähnlich wie in anderen Baracken, jedoch nicht ganz so beengt. Vor allem jedoch schwebte über den Zwillingen nicht, wie über allen anderen Häftlingen, das ständige Damoklesschwert des Lagerselektionen und der alltäglichen Gewalt: Sie wurden nicht zu Zwangsarbeit herangezogen, hatten keine Lagerstrafen zu gewärtigen und wurden nicht geschlagen. Sie waren quasi Mengeles Privateigentum, und so lange sie ihm lebendig mehr nutzten als tot, standen sie unter seinem Schutz und hatten nichts zu fürchten - außer Mengele selbst.

112 BAB, BDC, Mengele, Beurteilung von Dr. Josef Mengele, 19. 8. 1944.

113 Vgl. Völklein, Mengele, S. 144-157; Kubica, Mengele, S. 380-405; Strzelecka, Die Experimente, S. 435-439; außerdem Lagnando/Dekel, Zwillinge, S. 45-66. 
Nach der Ankunft im Lager mußten die Zwillinge zunächst einen detaillierten Fragebogen ausfüllen, der offenbar vom Berliner KWI stammte und anschließend auch dorthin zurückgesandt wurde. ${ }^{114}$ In der Waschbaracke (im Lagerjargon "Sauna" genannt) hinter Block 32 des Zigeunerlagers hatte sich Mengele schon bald nach seiner Ankunft ein Untersuchungs- und ein Arbeitslabor eingerichtet ${ }^{115}$, das im November 1944 in die Baracke 15 des Männerkrankenbaulagers (BIIf) verlegt wurde. Dort wurden die Zwillinge vermessen, anthropologische Merkmale (etwa die Form des Mundes, der Nase, der Ohrmuscheln und die Augen- und Hautfarbe) dokumentiert und mit dem jeweils anderen Zwilling verglichen. Diese Untersuchungen nahm Mengele zum Teil selbst vor, gestützt auf eine ganze Reihe von Häftlingen mit geeigneten Qualifikationen; im März 1944 entdeckte er zu seiner großen Freude im Revier des Frauenlagers die an Typhus erkrankte, renommierte polnische Anthropologien Dr. Martina Puzyna, die er gesund pflegen ließ und anschließend als seine Assistentin mit der Vermessung der Zwillinge betraute. Während der Prozedur, die sich oft über mehrere Stunden hinzog, standen die Kinder nackt in dem unbeheizten Labor; sie wurden fotografiert, geröntgt und einzelne Körperteile gezeichnet. Die gesammelten Daten wurden in eine 96 Punkte je Kind umfassende Kartei aufgenommen. Häftlingsärzte mit entsprechenden medizinischen Fachqualifikationen testeten außerdem Sehkraft und Gehör und fertigten Abdrücke des Kiefers. Einige Untersuchungen wurden regelmäßig wiederholt; dazu gehörte die Entnahme von Proben sämtlicher Körperausscheidungen und von Blut.

Mit diesen Untersuchungen gab sich Mengele jedoch nicht zufrieden. Auf morphologischem Gebiet nahm er Bluttransfusionen zwischen Zwillingen vor und injizierte Krankheitserreger und Fremdstoffe, um die Reaktionen der Geschwister vergleichen zu können. In chirurgischen Experimenten nahm er die unterschiedlichsten Operationen und Eingriffe an seinen Opfern vor (bzw. ließ sie von Häftlingsärzten in seiner Anwesenheit vornehmen), häufig ohne Narkose: ihn interessierte auch die unterschiedliche Reaktion der Zwillinge auf Schmerz. Vera Alexander, die als jüdischer Funktionshäftling in der Zwillingsbaracke im Zigeunerlager eingesetzt war, berichtet von einem Zwillingspaar, das ein besonders grausames Schicksal zu erleiden hatte: „Guido und Nina [waren] kaum älter als vier Jahre. Mengele holte sie $\mathrm{ab}$ und brachte sie auf eine perverse Weise verstümmelt zurück. Sie waren - wie Siamesische Zwillinge - am Rücken zusammengenäht. [...] Ihre Wunden eiterten, sie schrien Tag und Nacht. Irgendwie konnte ihre Mutter [...] Morphium besorgen und so dem Leiden ihrer Kinder ein Ende bereiten. "116 Moshe Ofer, ein damals zwölfjähriger Zwilling, der Mengele und Auschwitz überlebte, berichtet, der Lagerarzt habe ihn und seinen Bruder Tibi „wie ein guter Onkel [...] besucht und uns Schokolade mitgebracht. Bevor er uns mit Skalpell und Spritze traktierte, sagte er: ,Keine Angst, euch passiert nichts'. Er hat an unseren Hoden herumgeschnitten, uns Chemikalien injiziert und an Tibis Wirbelsäule operiert. Nach den Experimenten brachte er uns Geschenke. Noch heute sehe ich ihn durch die Tür kommen und bin

114 Vgl. die Aussage Zvi Spiegels („Zwillingsvater“), der für die Betreuung der männlichen

Zwillinge im Männerkrankenbaulager zuständig war und vor allem den jüngeren Kindern, die mit dem Fragebogen überfordert waren, beim Ausfüllen half; zit. in: Lagnando/Dekel, Zwillinge, S. 52.

115 Vgl. den Grundriß bei Kubica, Mengele, S. 391.

116 Zit. nach Kubica, Mengele, S. 403. 
vor Schrecken starr. Bei späteren Versuchen ließ er Nadeln in unsere Köpfe stecken [dabei dürfte es sich um eine Lumbalpunktion gebandelt haben]. Die Narben der Einstiche sind immer noch zu sehen. Einmal holte er Tibi ganz alleine. Mein Bruder blieb ein paar Tage weg. Als man ihn wiederbrachte, war sein Kopf unter einem riesigen Verband verborgen. Mein Bruder starb in meinen Armen."117

Die wenigsten, die ihren Zwilling verloren, überlebten. In der Regel tötete Mengele nach dem Tod des einen auch den anderen, um anschließend eine vergleichende Sektion der Leichen vornehmen zu lassen. In einer Rezension, die er 1941 noch in Frankfurt verfaßt hatte, hatte er bedauert, daß der Autor bei seinen röntgenologischen Untersuchungen "nicht jeweils von einem Probanden ausgegangen [sei], bei dem die Diagnose durch Authopsie gesichert war"118. Nun wollte Mengele damals sicherlich nicht andeuten, der Arzt hätte seine Probanden ermorden sollen - dennoch zeigt diese Passage, welche ungeahnten und unbegrenzten Möglichkeiten Auschwitz in den Augen Mengeles bot. Seit Ende Juni 1944 waren die Mengele so wichtigen Sektionen Aufgabe des ungarischen Pathologen Miklós Nyiszli. ${ }^{119}$ Mengele sorgte für beste Arbeitsbedingungen: 1944 wurde auf seine Anweisung hin ein modern ausgestattetes Prosektionslabor direkt neben dem Krematorium II neu errichtet. Nyiszli berichtet, daß ein Teil der Präparate, die er aus den Leichen gewinnen mußte, verpackt und mit dem Vermerk „Eilig, kriegswichtiger Inhalt" nach Berlin an Verschuers KWI für Anthropologie versandt wurde. ${ }^{120}$ Auch eine Vielzahl von Blutproben ging nach Berlin, und im April 1944 erhielt die Zusammenarbeit Mengeles mit von Verschuer und seinem Institut quasi offiziellen Charakter. Mengeles Mentor meldete der Deutschen Forschungsgemeinschaft (DFG), die Verschuers Forschungsprojekt über "Spezifische Eiweißkörper" finanzierte, daß als „Mitarbeiter in diesem Forschungszweig“ nunmehr „mein Assistent Dr. med. et Dr. phil. Mengele eingetreten"121 sei. Weiter schrieb Verschuer: „Er ist als Hauptsturmführer und Lagerarzt im Konzentrationslager Auschwitz eingesetzt. Mit Genehmigung des Reichsführers SS werden anthropologische Untersuchungen an verschiedenen Rassengruppen dieses Konzentrationslagers durchgeführt und die Blutproben zur Bearbeitung an mein Laboratorium geschickt." 1946 bestätigte von Verschuer, für seine Forschung über „die individuelle Spezifizität der Serum-Eiweißkörper und die Frage ihrer erblichen Bedingtheit“ habe er „Blutproben von Menschen verschiedener geographischer Herkunft“ gebraucht. „Damals besuchte mich mein früherer Assistent Dr. M[engele] und bot mir an, solche Blutproben aus dem Rahmen seiner ärztlichen Tätigkeit im Lazarett des Lagers Auschwitz zur Verfügung zu stellen. Auf diese Weise habe ich im Laufe der Zeit, natürlich nicht in regelmäßigen Abständen einige Sendungen von je 20-30 Blutproben zu je 5-10 ccm erhalten."122

Noch mindestens eine weitere Forscherin an von Verschuers Institut war ebenfalls von Mengeles Zuarbeit abhängig. Karin Magnussen arbeitete zur Heterochromie der Iris und stand vor dem Problem, daß ihr „Forschungsmaterial“, Zwillinge,

117 Zit. nach ebenda.

118 Mengele, Rezension: von Knorre.

119 Nyiszli, Jenseits.

120 Vgl. ebenda, S. 44-46; zu Mengeles Kontakten zum KWI vgl. außerdem Sachse/Massin, Forschung, S. 23-26.

121 Zit. nach Sachse/Massin, Forschung, S. 23.

122 Zit. nach ebenda. 
die jeweils links und rechts unterschiedliche Augenfarben hatten, nach Auschwitz deportiert worden waren. Dennoch habe sie ihre „Forschungsaufgabe durchgeführt, obgleich mir nach Internierung der Heterochromie-Sippe in Auschwitz jeder Zugang zu den Mitgliedern dieser Sippe verschlossen war, und zwar war das nur durch die Hilfe von Dr. Mengele möglich, der zufällig als Arzt an das Lager kommandiert war." 123 Magnussen verschwieg bei dieser Aussage vor der Spruchkammer im Jahr 1949 allerdings wohlweislich, daß sich der Zugang zu ihrem Forschungsmaterial nun erheblich anders gestaltete als zuvor: Es waren nicht etwa Fotografien, die Mengele nach Berlin schickte, sondern die herauspräparierten Augäpfel der extra zu diesem Zweck getöteten Kinder. Auch Mengele selbst befaßte sich mit den Augen seiner Opfer. Ihm ging es um die Frage, ob sich durch die Einträufelung chemischer Substanzen ins Auge die Farbe der Iris ändern ließe. Seine Opfer - wiederum hauptsächlich Kinder - litten furchtbare Schmerzen, einige verloren ihr Augenlicht, manche durch Eiterungen und Entzündungen ihr Leben.

Neben Zwillingen interessierte sich der Anthropologe Mengele in besonderem Maße für mißgebildete oder zwergwüchsige Menschen. ${ }^{124} \mathrm{Ihr}$ Schicksal glich dem der Zwillinge, ihre Besonderheit machte sie zum willkommenen Studienobjekt. Sie mußten ähnliche Untersuchungen über sich ergehen lassen, bevor nach ihrer Ermordung ihre Skelette herauspräpariert und ebenfalls nach Berlin geschickt wurden. Am 19. Mai 1944 traf die ungarische Artistenfamilie Ovitz ${ }^{125}$ in Auschwitz ein, zu der neben einigen normal gewachsenen auch sieben zwergwüchsige Familienangehörige zählten. Schon auf der Rampe zeigten sie den SS-Männern Reklamefotos ihrer Truppe. Die Familie wurde von der Selektion zurückgestellt und Mengele verständigt, der bei seinem Eintreffen sein Glück kaum fassen konnte und sich freute, daß ihm diese Familie „für zwanzig Jahre Arbeit geben" 126 werde. Die normal gewachsenen Artisten verdankten der Tatsache, daß Mengele die vollständige Familie aus Vergleichsgründen als wertvolles Studienobjekt betrachtete, ihr Leben. Auch sie mußten den geschilderten Untersuchungskanon über sich ergehen lassen. Zudem lebten sie in der ständigen Angst ermordet zu werden.

\section{1945-1979: Flucht und Verstecke}

Als die russischen Truppen Mitte Januar 1945 kurz vor dem rund 50 Kilometer entfernten Krakau standen und in Auschwitz der letzte Abendappell stattfand, suchte Mengele in seinen Arbeitsräumen die Ergebnisse seiner Forschungen zusammen, bestieg ein Auto und floh in Richtung Westen. 127 Über den weiteren Ablauf der Ereignisse bis zum 2. Mai 1945, an dem Mengele bei einer Wehrmachtseinheit Unterschlupf fand, herrscht erneut - wie schon über die drei Jahre vor seiner Ver-

123 Zit. nach ebenda. Vgl. zu den Forschungen Magnussens auch Hesse, Augen.

124 Vgl. Kubica, Mengele, S. 408; Völklein, Mengele, S. 150 und $156 \mathrm{f}$.

125 Völklein nennt als Namen dieser Artistenfamilie fälschlich Moskovits (Völklein, Mengele, S. 156f.); es handelt sich jedoch ganz offensichtlich um die Familie Ovits. Vgl. zur Lebensgeschichte dieser Artistenfamilie: Koren/Negev, Riesen.

126 Zit. nach Völklein, Mengele, S. 157.

$127 \mathrm{Vgl}$. Sta F/M, Az 4 Js 340/68, Erm.A., Bd. XIII, Bl. 12-19, Aussage Martina Puzyna, 31. 10. 1972; Czech, Kalendarium, S. 968, und Völklein, Mengele, S. 190. 
setzung nach Auschwitz - einige Unklarheit in der bisher verfügbaren Literatur. Hierzu einige Hinweise:

Ulrich Völklein übernimmt in seiner Biograpahie die Angabe der Staatsanwaltschaft Frankfurt, wonach Josef Mengele seit dem 18. Januar 1945 in Groß-Rosen ${ }^{128}$ als Lagerarzt geführt worden sei. ${ }^{129}$ Tatsächlich kann Mengele bereits am Tag nach seiner überstürzten Flucht aus Auschwitz in dem etwa 250 Kilometer nordwestlich gelegenen KL Groß-Rosen eingetroffen sein. Zu diesem Zeitpunkt hat er dort allerdings sicher noch keine offizielle Funktion (wie die eines Lagerarztes) bekleidet, dazu war die Zeit zu knapp; möglicherweise hat er aber „ausgeholfen“, denn GroßRosen war zu diesem Zeitpunkt eines der Evakuierungsziele für Häftlinge aus Auschwitz und völlig überfüllt. ${ }^{130}$ Dr. Horst Fischer ${ }^{131}$, der ebenfalls Arzt in Auschwitz gewesen war, traf Mengele am 23. oder 24. Januar in Groß-Rosen wieder, und beide fuhren zusammen mit einem weiteren SS-Arzt „nach Oranienburg zum leitenden Arzt der KZ Dr. Lolling“132. Dort hat Fischer Mengele „letztmalig gesehen. Mengele wurde ca. Ende Januar 1945 als 1. Lagerarzt wieder nach Groß-Rosen geschickt "133. Mengele kann sich also unmittelbar nach seiner Flucht aus Auschwitz maximal vier oder fünf Tage in Groß-Rosen aufgehalten haben. Deshalb ist auch Isabell Sprengers Spekulation zurückzuweisen, der „berüchtigte SS-Arzt“ Mengele könnte identisch sein mit dem Lagerführer des Außenlagers Kratzau I, in dem es „im Vergleich zu anderen Lagern ungewöhnlich brutal zugegangen " 134 sei.

Mengele fuhr also am 23. oder 24. Januar mit zwei Kollegen von Auschwitz nach Berlin, um bei Dr. Lolling, dem Chef des Amtes D III im Wirtschafts- und Verwaltungshauptamt, Anweisungen für seinen weiteren Einsatz einzuholen. Erst dort entschied man, Mengele wieder nach Groß-Rosen zurückzuschicken. Allerdings, und hier irrt Fischer, sollte er dort nicht nur als einfacher Lagerarzt, sondern als SSStandortarzt eingesetzt werden - er übernahm damit die Stellung, die Eduard Wirths in Auschwitz bekleidet hatte und war damit nicht mehr nur für die Häftlinge zuständig, sondern auch und vor allem für die SS-Angehörigen. Mengele rückte also in der medizinischen Hierarchie der SS eine Stufe nach oben. Dies belegt ein Schreiben Mengeles an die Ärztliche Bezirksvereinigung Waldenburg, in dem er „als Nachfolger des ab 6. Februar 1945 von hier versetzten SS-Hauptsturmführers Dr. Friedrich Entreß“ bittet, „die Genehmigung zur Ausübung der Kassenpraxis im hiesigen Bezirk auf mich übertragen zu wollen. Gez. Josef Mengele, SS-Hauptsturmführer und SS-Standortarzt Groß-Rosen."135

Josef Mengele hat seinen Vorgänger also am 6. Februar 1945 in Groß-Rosen abgelöst, doch kann er dort nicht lange geblieben sein, denn bereits zwei oder drei

128 Zum KL Groß-Rosen vgl. Sprenger, Groß-Rosen und Konieczny, Frauen.

$129 \mathrm{Vgl}$. Völklein, Mengele, S. 191, und Sta F/M, Az 4 Js 340/68, Fahnd.A., Schlußvermerk, 14. 7. 1986, S. 33.

130 Vgl. Strzelecki, Endphase und Strzelecki, Todesmarsch.

131 Vgl. S. 24.

132 BStU, MfS, ZA, ZU V 84, HA Bd. 5, Bl. 307, Eidesstattliche Versicherung Dr. Horst Fischers, 16. 5. 1966.

133 Ebenda.

134 Sprenger, Groß-Rosen, S. 283.

135 BAB, NS 4 GR 8, Schreiben Josef Mengeles an die Reichsärztekammer, Ärztliche Bezirksvereinigung Waldenburg betr. Übertragung der Kassenpraxis, 7.2. 1945, abgedruckt in: Tuchel, Inspektion, S. 163. 
Tage später, am 8. oder 9. Februar, begann die SS mit der Evakuierung des Lagers, das die Rote Armee am 13. Februar befreite. ${ }^{136}$ Völklein ist überzeugt, Mengele habe sich nach der Befreiung von Groß-Rosen, die er wie auch Posner und Ware fälschlicherweise und ohne Quellenangabe auf den 25 . Februar datiert ${ }^{137}$, mit einem der Häftlingstransporte in das KL Ravensbrück ${ }^{138}$ begeben. Er stützt sich dabei auf zwei Zeuginnen, die Mengele aus Auschwitz kannten und ihn in Ravensbrück selbst bzw. in Neustadt-Glewe, einem der Ravensbrücker Außenlager, wiedergetroffen haben wollen. ${ }^{139}$ Obwohl - wie dies auch Völklein sieht - beide Zeuginnen, trotz eines offensichtlichen Irrtums in der Datierung als grundsätzlich zuverlässig einzustufen sind, ist hier dennoch ein Irrtum möglich, wenn nicht sogar wahrscheinlich, denn es steht fest, daß Mengele sich am 2. Mai 1945 in Saaz in Nordböhmen in Wehrmachtsuniform dem Wehrmachtslazarett 2/591 angeschlossen hat. ${ }^{140}$ Soll der von Völklein rekonstruierte Ablauf der Ereignisse stimmen, hätte sich Mengele nur wenige Tage, nachdem er seinen neuen Posten als Standortarzt angetreten hatte, in das rund 350 Kilometer nordwestlich von Groß-Rosen gelegene Ravensbrück absetzen und Mitte April noch einmal über 100 Kilometer in westlicher Richtung zurücklegen müssen, um in das Außenlager Neustadt-Glewe zu gelangen. Dieses hätte er dann nur wenige Tage später erneut verlassen müssen, um kurz vor dem 25. April141 in entgegengesetzter Richtung zwischen den sich rasch annähernden Fronten der Amerikaner und Sowjets rund 375 Kilometer nach Südosten ins Sudetenland zu fliehen - ausgerechnet in ein Gebiet, das von der vorrückenden Roten Armee akut bedroht war. Noch dazu hätte er dies in dem vollen Bewußtsein tun müssen, daß "das wichtigste Ziel“ sein mußte, „nicht in russischer Kriegsgefangenschaft" $\mathrm{zu}$ enden und dort „um [das] Leben fürchten oder doch eine eingehende Überprüfung [der] zurückliegenden Jahre erwarten“ zu müssen, die man „bei den vermeintlich viel nachlässigeren Amerikanern sich zu ersparen"142 hoffte. Gerade Mengele, der eineinhalb Jahre an der Ostfront gekämpft und noch einmal die gleiche Zeit als Arzt in Auschwitz verbracht hatte, wußte, was die Rote Armee im Osten durchgemacht und mittlerweile vorgefunden hatte - und was seinesgleichen bei einer Gefangennahme durch die Russen zu befürchten hatte.

Wahrscheinlicher erscheint eine andere Möglichkeit, die aber einen Irrtum der bei Völklein zitierten Zeugen voraussetzt: Kurz vor der Befreiung des Hauptlagers Groß-Rosen wurde die dortige Kommandantur in das Außenlager Reichenau ${ }^{143}$

136 Vgl. Sprenger, Groß-Rosen, S. 296-298.

137 Vgl. Völklein, Mengele, S. 193, und Posner/Ware, Mengele, S. 82; Posner und Ware handeln diesen Zeitraum in wenigen Zeilen ab und gehen fälschlicherweise davon aus, Mengele habe sich nach seiner Flucht aus Groß-Rosen (s.u.) direkt dem Wehrmachtslazarett angeschlossen und habe bei dieser Einheit die zwei Monate bis Kriegsende verbracht.

$138 \mathrm{Zu}$ Ravensbrück vgl. Philipp, Kalendarium; Strebel, Ravensbrück.

139 Vgl. ebenda, S. 192-194.

140 Zur Datierung vgl. schlüssig Völklein, Mengele, S. 194; Völklein schreibt, Mengele sei an einem „nicht genannten Ort" auf das Lazarett gestoßen, während im Bericht des OSI der Ort Saaz (heute Žatec in der tschechischen Republik) genannt wird; vgl. In the Matter of Josef Mengele 1, S. 26.

141 An diesem Tag trafen sich Amerikaner und Russen an der Elbe, der Weg nach Süden wäre also versperrt gewesen.

142 Josef Mengele in seinen Aufzeichnungen, zit. nach Völklein, Mengele, S. 197.

143 Nahe Gablonz an der Neiße (heute Jablonec in der Tschechischen Republik). 
verlegt und leitete von dort die übrig gebliebenen Außenlager, bis die Sowjets am 8./9. Mai auch dieses Lager erreichten.144 Mengele war als Standortarzt erst seit wenigen Tagen Mitglied der Kommandantur und dürfte seinen neuen Posten wohl kaum so schnell wieder verlassen haben - er hätte dies vermutlich weder gekonnt noch gewollt.

Für diese These spricht auch ein Besuch Mengeles in dem von Reichenau etwa $30 \mathrm{~km}$ entfernten Außenlager Ober-Hohenelbe ${ }^{145}$, wo eine Zeugin, die in Auschwitz mit ihrer Z willingsschwester als Versuchsobjekt mißbraucht worden war, eine Selektion Mengeles im Krankenbau überlebte. Dieses Außenlager ist von Groß-Rosen mit 70 Kilometern relativ weit entfernt und liegt noch dazu auf der anderen Seite des Erzgebirges. Wenn Mengele nicht mit der Kommandantur nach Reichenau ging, hätte dieser Besuch in den wenigen Tagen stattfinden müssen, die sich Mengele direkt nach seiner Flucht aus Auschwitz im Hauptlager aufgehalten hat und die durch die beginnende Evakuierung chaotisch gewesen sein dürften. Das Außenlager Ober-Hohenelbe wurde dagegen, wie Reichenau, erst Anfang Mai befreit - Zeit genug also für Mengele, vom neuen Sitz der Kommandantur aus das nun relativ nahe gelegene Außenlager zu besuchen. Zudem kann er, wenn er sich nach der Evakuierung von Groß-Rosen zusammen mit dem Rest der Kommandantur in Reichenau aufgehalten hat, gegen Ende April vor der heranrückenden Roten Armee direkt in Richtung Westen geflohen sein, um am 2. Mai in der Nähe des fast genau 120 Kilometer westlich gelegenen Saaz in Wehrmachtsuniform auf das Wehrmachts-Feldlazarett 2/591 zu stoßen.

Einer der Angehörigen dieses Feldlazaretts war Dr. Otto-Hans Kahler, der vor dem Krieg ebenfalls an Verschuers Frankfurter Institut tätig gewesen war und den Mengele kannte. Er setzte sich bei dem Kommandanten für seinen alten Kollegen ein, so daß diesem erlaubt wurde, sich der Einheit anzuschließen. Das Lazarett zog sich weiter Richtung Westen zurück, passierte Karlsbad ${ }^{146}$ und hielt sich dann mit Erlaubnis der Amerikaner etwa sechs Wochen in einem Waldgebiet im Erzgebirge auf, das im „Niemandsland“ lag, einem Gebiet, das zwar zum amerikanischen Einflußbereich gehörte, aber östlich der Besatzungslinie lag. Mengele wurde von Kahler getrennt und hielt sich nun an Dr. Fritz Ulmann. Kahler sagte später den Ermittlern des OSI, Mengele habe zu diesem Zeitpunkt unter starken Depressionen gelitten und sogar an Selbstmord gedacht; er habe sich deswegen an Dr. Fritz Ulmann, einen Neurologen mit psychologischen Kenntnissen, gewandt. Kahler spekulierte in seiner Aussage nicht über den Grund von Mengeles Depressionen, deutete aber an, daß Mengele zu diesem Zeitpunkt offen über die Selektionen in Auschwitz gesprochen habe. Ob dies als - der einzige vorhandene-Anhaltspunkt gewertet werden kann, daß Mengele sich im Nachhinein mit seinen Taten auseinandergesetzt oder gar so etwas wie ein Schuldbewußtsein entwickelt hat, ist fraglich. Wahrscheinlicher ist, daß Mengele mit seiner Entlarvung rechnete und deshalb in Depressionen verfiel.147 Mitte Juni 1945 kontaktierten die Amerikaner die Einheit und wiesen sie an, sich nun weiter nach Westen zurückzuziehen, da das Gebiet an die

144 Vgl. Sprenger, Groß-Rosen, S. 299.

145 Horejsi Vrchlabi am Südrand des Riesengebirges in der heutigen Tschechischen Republik.

146 Heute Karlovy Vary.

$147 \mathrm{Vgl}$. In the Matter of Josef Mengele 1, S. $26 \mathrm{f}$. 
Rote Armee fallen sollte. Nach dem Rückzug auf bayerisches Gebiet wurden die Soldaten und Mengele, der keine Papiere bei sich trug und falsche Namen benutzte, zunächst in dem Lager Schauenstein bei Hof, später in Helmbrechts interniert. ${ }^{148}$

Nach insgesamt rund sechs Wochen Internierung wurde Mengele in der ersten Augustwoche entlassen. Es kann als gesichert gelten, daß die Amerikaner zu diesem Zeitpunkt nicht wußten, wen sie da entließen, eine „geheime Verständigung zwischen den amerikanischen Behörden" und dem "Hauptkriegsverbrecher"149 kann ausgeschlossen werden. ${ }^{150}$ Die Kriegsverbrecherlisten, auf denen Mengeles Name seit Mai 1945 auftauchte ${ }^{151}$, erreichten auf Grund der chaotischen Nachkriegsverhältnisse nicht rechtzeitig die Verantwortlichen vor Ort, die mit den zu dieser Zeit vorgenommenen Massenentlassungen ohnehin völlig überlastet waren. Seine $\mathrm{Pa}$ piere hatte Mengele vernichtet, er gehörte zu einem Wehrmachtslazarett und hatte in dieser Einheit Bekannte, die für ihn bürgten. Am wichtigsten jedoch war eine Tatsache, die er seiner persönlichen Eitelkeit zu verdanken hatte: Er hatte keine Blutgruppen-Tätowierung und war deshalb für die Amerikaner nicht als SS-Angehöriger zu erkennen - andernfalls wäre er nicht entlassen, sondern in „automatic arrest" genommen worden. 152

Nach seiner Entlassung wurde Mengele, der mittlerweile über gefälschte Entlassungspapiere auf den Namen Fritz Hollmann ${ }^{153}$ verfügte, Mitte August in der Nähe von Ingolstadt abgesetzt. Von dort aus machte er sich auf den Weg in Richtung Donauwörth ${ }^{154}$, wo er einen Schulfreund namens Albert Miller aufsuchte, der sich dort als Tierarzt niedergelassen hatte. Bald ging es weiter donauaufwärts - sehr vorsichtig, um nicht einer Militärstreife zu begegnen oder in der Günzburger Gegend von jemandem erkannt zu werden. 155

148 Vgl. ebenda, S. 26-32.

149 Posner/Ware, Mengele, S. 87. Posner und Ware sind nicht die einzigen, die in diese Richtung spekulieren.

150 Vgl. die ausführliche Untersuchung dieser Frage in: In the Matter of Josef Mengele 1, S. 30-53.

151 „MENGELE, Joseph, Dr., SS. Hauptsturmfuehrer and Lagerarzt, Oswiecim KL, June 1940 to January 1945, Mass murder, and other crimes" (United Nations War Crimes Commission, Part I: Eighth List of War Criminals (Germans), May 1945, S. 27. Kopie in: In the Matter of Josef Mengele 2, S. 74.

152 Mengele hatte sie angeblich, wie andere auch, aus Eitelkeit verweigert. Vgl. die Angaben Rolf Mengeles in: So viele halfen ihm, in: Bunte, 27. 6. 1985, S. 28. Vgl. außerdem: In the Matter of Josef Mengele 1, S. 53.

153 Mengele hatte in den Entlassungspapieren Ulmanns dessen Namen abgeändert; Ulmann selbst dürfte unter Vorlage seines Wehrpasses keine Probleme gehabt haben, neue Papiere zu erhalten.

154 Von Ingolstadt ca. $50 \mathrm{~km}$ donauaufwärts etwa auf halbem Wege nach Günzburg gelegen. Zunächst war Mengele zu Fuß unterwegs, später traf er auf einen Bauern mit zwei Fahrrädern, der ebenfalls nach Donauwörth wollte und Mengele mit einem der beiden Räder fahren ließ.

$155 \mathrm{Vgl}$. In the Matter of Josef Mengele 1, S. $62 \mathrm{f}$. sowie das Interview mit Millers Frau in: Gesucht wird... Josef Mengele, Fernsehsendung von Felix Kuballa unter Mitarbeit von Hermann G. Abmayr/René Werner Gallé, WDR 1985. Völklein, der als Quelle nur die Fernsehsendung angibt, schreibt, daß Miller wegen seiner eigenen Mitgliedschaft in der NSDAP verhaftet worden sei und Mengele dies im Nebenzimmer miterlebt habe. Davon ist in dem Fernsehinterview nicht die Rede; eine Verhaftung Millers wird zwar in dem Bericht 
Wenig später traf Mengele in Günzburg ein und versteckte sich für einige Wochen in den umliegenden Wäldern, während ihn die Familie mit Lebensmitteln versorgte. ${ }^{156}$ Auf Dauer konnte er dort nicht bleiben und machte sich deshalb Ende September auf den Weg nach München, wo er erneut mit Fritz Ulmann Kontakt aufnahm. Dessen Schwager riet ihm, sich auf einem einsam liegenden Gehöft in Oberbayern zu verstecken. Mengele folgte diesem Rat, und irgendwann zwischen Anfang und Mitte Oktober verdingte sich Dr. phil. et Dr. med. Josef Mengele als Knecht auf dem Lechnerhof in Mangolding ${ }^{157}$ und mußte von nun an für seinen Lebensunterhalt physisch arbeiten. Als erste landwirtschaftliche Aufgabe wies ihm der Bauer in der "Probezeit" das Sortieren von Kartoffeln zu. Die großen sollten als Speisekartoffeln, die mittelgroßen als Saatkartoffeln und die kleinsten als Schweinefutter genutzt werden. Er ging auch diese Aufgabe wissenschaftlich an und scheint sich dabei, wie eine Reminiszenz in seinen Erinnerungen vermuten läßt, an seine Tätigkeit in Auschwitz erinnert zu haben; die Beschreibung seines Vorgehens liest sich in seinen Aufzeichnungen so: „Er $\mathrm{Er}^{158}$ fand schnell die zweckmäßigste Sortierund Abtransportmethode in die drei Kellerfensteröffnungen heraus und bemerkte ebenso rasch, daß [...] die Häufigkeit der verschiedenen Größen der binominalen Verteilung nach dem Gaußschen Diagramm folgt. Die mittelgroßen stellen also die große Masse, die ganz kleinen sind ebenso wie die ganz großen viel weniger häufig. Da man aber nicht so viel Saatkartoffeln benötigt und sie doch wohl vor allem der menschlichen Ernährung wegen anbaut, verschob Hans die Selektionsstraße der Speisekartoffeln ein bißchen nach den mittelgroßen zu." 159

Mengele erfüllte offenbar seinen ersten Auftrag zur Zufriedenheit des Bauern und durfte auf dem Lechnerhof bleiben. Dort kultivierte er während der folgenden drei Jahre sein Selbstmitleid: „Zwölf Arbeitsstunden / Und noch mehr Schwielen, Riß' und Schrunden, / Doch geistig trat ich kurz" ${ }^{160}$, dichtete der Akademiker, dessen ehrgeizige Karriereplanung ihn nun auf ein frisch gepflügtes Feld geführt hatte, wo er Mist verteilen mußte. Die harte körperliche Arbeit war ungewohnt, seine

des OSI erwähnt, allerdings war Mengele zu diesem Zeitpunkt schon nicht mehr in Donauwörth. Vgl. Völklein, Mengele, S. $198 \mathrm{f}$.

156 Vgl. Völklein, Mengele, S. 199 f.; In the Matter of Josef Mengele 1, S. 54-56, und die Angaben Rolf Mengeles in: So viele halfen ihm, in: Bunte, 27. 6. 1985. Vgl. zu Hinweisen auf eine angebliche Reise Mengeles in die sowjetische Besatzungszone nach Gera während dieser Zeit: In the Matter of Joseph Mengele 1, S. 64 f., Posner/Ware, Mengele, S. 85, und Völklein, Mengele, S. 321. Eine für Mengele derart riskante Reise zu einer angeblichen Geliebten auch unter der von Posner/Ware genannten und nicht näher belegten Voraussetzung, daß Mengele ihr seine Auschwitz-Aufzeichnungen anvertraut habe, ist unwahrscheinlich; überzeugender erscheint Völkleins Bewertung der vagen Hinweise in Mengeles biographischen Aufzeichnungen als Schutzbehauptungen mit dem naheliegenden Zweck, die Unterstützung durch seine Familie zu verschleiern.

157 Ein kleiner Weiler, etwa auf halbem Weg zwischen Rosenheim und dem Chiemsee gelegen.

158 Mengele schreibt wie immer in der dritten Person; der Deckname, den er in diesem Abschnitt verwendet, lautet „Hans“.

159 Zit. nach: Völklein, Mengele, S. 205. Der Abschnitt in Mengeles autobiographischen Aufzeichnungen, der die Zeit bis Ende 1946 beschreibt, ist mit dem Titel „Bauernzeit“ überschrieben und stammt aus den sechziger und siebziger Jahren (Sta F/M Az 4 Js 340/68, Aufz. Mengele, Heft 1-4: Bauernzeit). Vgl. zur Zeit in Mangolding außerdem Völklein, Mengele, S. 202-224; Posner/Ware, Mengele, S. 94-101, und In the Matter of Josef Mengele 1, S. 65-68.

160 Zit. nach: Völklein, Mengele, S. 207. 
Handgelenke schwollen an und die Sehnen schmerzten: „Aber es gibt kein Ausweichen und keine Flucht und keine Weigerung, denn es geht wieder um die bloße Existenz. Unerbittlich rücken die Furchen näher, und schonungslos zerschüttelt Hans mit der Gabel den Mist und verbeißt den höllischen Schmerz im Handgelenk. Die Tränen rinnen dem alten Soldaten über die Wangen, und er stellt sich mit dem Rücken zum Pflüger, wenn er vorbeikommt, damit er das weibische Versagen nicht bemerken soll.“161 Nach solchen Tagen beschlich „Hans“ dann „ein Gefühl der Gleichgültigkeit, der haltlosen, Wurstigkeit', von der es zur Selbstaufgabe nur noch ein Schritt ist"162.

Mengele blieb in Mangolding zunächst weitgehend isoliert. Er richtete sich in seinem Opferselbstbild ein, Reflexionen über seine Taten in Auschwitz sucht man in seinen Aufzeichnungen vergeblich. Stattdessen kultivierte und stabilisierte er in vielleicht fiktiven - Gesprächen mit dem Schwager Fritz Ulmanns, Dr. Johann Weigl ${ }^{163}$, sein eigenes, erschüttertes Weltbild. Erst der Krieg, den „das internationale Judentum Deutschland aufzwang“, habe „eine friedliche Lösung der Judenfrage vereitelt" 164 , schrieb Mengele. Immerhin allerdings sei „dieser Krieg wohl der erste unter arischen Völkern“ gewesen, „bei dem auch das jüdische, wie die anderen, sein Opfer bringen mußte" 165 . Ansonsten hatte er kaum Kontakt zur Außenwelt, die spärlichen Informationen, die ihn erreichten, stammten großteils aus dem Rosenheimer Anzeiger, der achtseitigen Lokalzeitung. Seine Familie hatte aus Sicherheitsgründen beschlossen, jegliche Verbindung zunächst zu vermeiden, und selbst am Weihnachtsfest 1945 blieb er ohne Nachrichten aus Günzburg. Auch vom Tod der Mutter am 28. Januar 1946 erfuhr er lange Zeit nichts. Erst im Sommer 1946, mit dem Besuch des Bruders Karl, erreichten ihn die ersten Nachrichten von der Familie.

Im Herbst kam erstmals auch seine Frau Irene, die ihm jedoch bei mehreren Besuchen zu verstehen gab, daß sie sich von ihm trennen wolle. Josef und Irene Mengele hatten bisher wenig Gelegenheit gehabt, ein Eheleben zu führen. Sie hatten im Juli 1939 geheiratet. Ein Jahr später war Mengele zur Wehrmacht eingezogen worden und hatte sich zur Waffen-SS gemeldet. Von nun an sahen sie sich nur noch, wenn Mengele Fronturlaub hatte. Irene fühlte sich einsam und suchte Trost bei einem anderen. Nachdem sie ihren Ehemann im Oktober 1944 in Auschwitz besucht hatte und nach dem Krieg immer mehr Informationen über die Geschehnisse in den Konzentrationslagern bekannt wurden, war ihr klar, daß er vermutlich nie nach Hause zurückkehren und ein normales Leben führen würde. Ihr war bewußt geworden, daß der Mengele, den sie vor dem Krieg geheiratet hatte, mit dem, der sich nun in Oberbayern versteckt hielt, nicht mehr viel gemein hatte. Er konnte sich den Alliierten stellen und seine Strafe auf sich nehmen, oder er würde sich für lange Zeit auf der Flucht befinden, immer in Angst, zufällig entdeckt zu werden. Dieses Leben wollte Irene Mengele sich und ihrem im März 1944 geborenen Sohn Rolf nicht zumuten. ${ }^{166}$ Mengele mußte dies akzeptieren und befleißigte sich einer historischen Sichtweise: „Mit dem Dritten Reich ging auch seine Ehe zu Ende, sie hatte

161 Zit. nach: Ebenda.

162 Zit. nach: Ebenda, S. 208.

163 In Mengeles Aufzeichnungen „Wieland“ genannt.

164 Zit. nach: Völklein, Mengele, S. 214.

165 Zit. nach: Ebenda, S. 213.

166 Vgl. Völklein, Mengele, S. 221 f., und Posner/Ware, Mengele, S. 100 f. 
einfach $z u$ bestehen aufgehört, wie vieles andere. Trümmer waren übriggeblieben, auch von seiner Ehe. Man mußte sie wegräumen und Neues errichten. "167 Dieses Neue begann sich nun immer deutlicher abzuzeichnen: Irene hatte ihm dringend empfohlen, nach Südamerika auszuwandern, und die Neuigkeiten, die Mengele aus dem Rosenheimer Anzeiger erfuhr, machten ihm klar, daß er ihrem Vorschlag folgen mußte: Die 1946 im Nürnberger Prozeß gegen die Hauptkriegsverbrecher und, noch eindringlicher, die 1947 im Ärzteprozeß gefällten Urteile ${ }^{168}$ mußten ihm deutlich vor Augen führen, was er im Falle einer Verhaftung zu erwarten hatte.

Am 1. August 1948 verließ Mengele den Lechnerhof. Wo er sich in den folgenden Wochen und Monaten aufgehalten hat, ist unklar - vermutlich hat er sich erneut in den Wäldern um Günzburg versteckt gehalten. ${ }^{169}$ Dies konnte jedoch nicht zum Dauerzustand werden, und so beschaffte die Familie für die so kurz nach der Währungsreform enorme Summe von 7000 DM einen gefälschten Paß, der aber so dilettantisch angefertigt war, daß er praktisch wertlos war. ${ }^{170}$ Außerdem sorgte man hinsichtlich der Firma vor: Josef verzichtete notariell auf den ihm zustehenden Erbteil, weil man fürchtete, das Vermögen von Kriegsverbrechern könnte beschlagnahmt werden. ${ }^{171}$ Mittlerweile hatte sich Mengele entschlossen, im Argentinien Juan Domingo Peróns Zuflucht zu suchen. Dort hielt sich bereits eine ganze Reihe prominenter Nationalsozialisten auf (darunter Adolf Eichmann), und das ehemalige Fliegerass der Luftwaffe, Hans Ulrich Rudel ${ }^{172}$, hatte das „Kameradenwerk“ ins Leben gerufen, um Fluchthilfe zu leisten und Neuankömmlingen die Eingewöhnungsphase zu erleichtern. Auch an Josef Mengeles Flucht dürfte diese Organisation ihren Anteil gehabt haben.173

Am 15. April 1949, dem Karfreitag, waren alle Vorbereitungen abgeschlossen; Josef Mengele verließ mit Ziel Südamerika das Gebiet des vormaligen Deutschen Reiches und überquerte auf abseitigen Wegen den Brenner, die Grenze zu Italien. ${ }^{174}$ Auf durchaus abenteuerliche Weise gelangte er nach Sterzing, wo er sich vier Wochen lang aufhielt und von seinen Kontaktmännern mit gefälschten Ausweispapieren auf den Namen Helmut Gregor, geboren in Südtirol, versehen

167 Mengele in seinen Aufzeichnungen, zit. nach: Völklein, Mengele, S. 222.

168 Zum Nürnberger Ärzteprozeß vgl. Mitscherlich/Mielke, Medizin; Ebbinghaus/Dörner, Vernichten, und Oppitz, Medizinverbrechen.

169 Vgl. Völklein, Mengele, S. 225, und Posner/Ware, Mengele, S. 115 f.

170 Vgl. die Angaben Rolf Mengeles in: So viele halfen ihm, in: Bunte, 27. 6. 1985, S. 32.

171 Vgl. ebenda

172 Geb. 1916, gest. 1982; Oberst der Luftwaffe, 2530 Feindflüge; seit Verleihung des eigens für ihn geschaffenen „Goldenen Eichenlaubs mit Schwertern und Brillianten zum Ritterkreuz des Eisernen Kreuzes" durch Hitler am 1. 1. 1945 höchstdekorierter Soldat der Wehrmacht; Unterschenkelamputation nach Abschuß im Februar 1945; nach Kriegsende Auswanderung nach Argentinien; dort als Luftfahrtberater für Perón tätig und in der deutschen Emigrantenszene aktiv; 1951 Rückkehr nach Deutschland, 1953 Hamburger Spitzenkandidat der neonazistischen Deutschen Reichspartei für die Bundestagswahl 1953; Mitte der 1950er Jahre erneute Auswanderung nach Paraguay, nun Tätigkeit für den paraguayanischen Diktator Alfredo Stroessner; 1960 endgültige Rückkehr nach Europa; Idol der rechten Szene; 1982 verstorben.

173 Vgl. Völklein, Mengele, S. 226f., und Posner/Ware, Mengele, S. 116.

174 Vgl. zur Flucht Mengeles: Völklein, Mengele, S. 227-235, und Posner/Ware, Mengele, S. 114-122. Mengele selbst beschreibt seine Flucht in seinen autobiographischen Aufzeichnungen: F/M Az 4 Js 340/68, Aufz. Mengele, Heft 5: [ohne Titel]. 
wurde. Anschließend führte Mengeles vorbereitete Fluchtroute über Bozen nach Genua, wo ihm das Schweizer Konsulat auf Grundlage dieser gefälschten Identitätskarte trotz fadenscheinigster Begründung einen Rotkreuzpaß ${ }^{175}$ ausstellte. Ein beinahe mißglückter Bestechungsversuch führte dazu, daß Mengeles Flucht in der italienischen Hafenstadt fast zu Ende gewesen wäre: Er brauchte noch ein italienisches Ausreisevisum, doch der korrupte Fremdenkommissar, der dieses normalerweise gegen entsprechende Entlohnung auszustellen pflegte, war verreist. Der vertretende Beamte war nicht bestechlich, gab Mengele sein Geld zurück und führte ihn seinem Vorgesetzten vor. Dieser hielt Mengeles Ausweis nicht zuletzt wegen dessen schlechter Italienischkenntnisse für gefälscht und ließ in verhaften. Vier Tage blieb Mengele inhaftiert, dann war der korrupte Fremdenkommissar zurück, und die Sache wurde bereinigt. ${ }^{176}$ Am 25. Mai 1949177 konnte der ehemalige Lagerarzt endlich sein Schiff, die "North King", besteigen und Europa in Richtung Argentinien verlassen.

Am 20. Juni 1949 erreichte die North King Buenos Aires. Dort wurde Mengele nach einigen anfänglichen Schwierigkeiten im Haus des NS-Sympathisanten Gerald Malbranc aufgenommen, und am 17. September erhielt Mengele einen argentinischen Fremdenausweis ${ }^{178}$, ausgestellt auf den Namen Helmut Gregor. In Malbrancs Haus verkehrte neben der Prominenz der deutschen Kolonie auch die der einheimischen, durchaus einflußreichen rechtsextremen Szene. So lernte Mengele im Laufe der Zeit etwa Hans-Ulrich Rudel, Willem Sassen ${ }^{179}$ und Frederico Haase ${ }^{180}$ kennen und konnte deren vielfältige Verbindungen und Ratschläge nutzen. Auch mit Adolf Eichmann traf Mengele zusammen, konnte sich mit ihm aber offenbar nie richtig anfreunden: Mengele habe „das unterschwellige Fluidum der Angst" nicht ausstehen können, das die "mitleiderregende Figur" umgab, die ,in schäbiger Zivilkleidung durch Buenos Aires schlurfte"181. Willem Sassen, der Mengele und Eichmann 1952 einander vorgestellt haben will, betont, diese seien ,in ihrer Art zwei völlig verschiedene Menschen, Eichmann und Mengele. Zumal

175 Comitato Internazionale della Croce Rossa, Genova, Richiesta di Titolo di Viaggio, 16. 5. 1949, Kopie in: In the Matter of Josef Mengele 2, S. $106 \mathrm{f}$., und Kubica, Mengele, S. $424 \mathrm{f}$.

176 Vgl. Völklein, Mengele, S. $234 \mathrm{f}$.

177 Über dieses Datum besteht einige Unklarheit. So behaupten etwa Posner und Ware ohne Beleg, Mengele habe drei Wochen im Gefängnis gesessen und Genua erst Mitte Juli verlassen. Dem Fazit Völkleins, das Abreisedatum sei nicht mehr zuverlässig zu rekonstruieren, ist ebenfalls zu widersprechen. Auf Mengeles Rotkreuzpaß ist das Datum der bereits reservierten Schiffspassage angegeben („Emigrazione: per Argentine in proprio Passaggio prenotato sulla $\mathrm{m} / \mathrm{n}$,NOR'TH KING' [...] partenza 25/5/49“. Vgl. Fn. 46). Es gibt keinen Grund, dieses Datum anzuzweifeln, da es zu dem von Mengele in seinen Aufzeichnungen beschriebenen Ablauf seiner Flucht exakt paßt, wonach er Mitte Mai Sterzing verlassen und sich anschließend sieben Tage in Genua aufgehalten haben will, davon vier in Haft. Vgl. Völklein, Mengele, S. 323; Posner/Ware, Mengele, S. $121 \mathrm{f}$.

178 Nr. 394048, ausgestellt am 17.9. 1949, Adresse: Calle Arenales 2460, Stadtteil Florida, Buenos Aires (die Adresse Malbrancs). Vgl. Völklein, Mengele, S. $239 \mathrm{f}$.

179 Geboren in Holland, als ehemaliges Mitglied der Waffen-SS wegen Kriegsverbrechen gesucht.

180 Architekt deutscher Abstammung, der zur Lokalprominenz gehörte; besonders an der deutschen Klassik in Literatur und Musik interessiert; befriedigte Mengeles geistige und kulturelle Bedürfnisse durch gemeinsame Besuche von Konzerten, Vorträgen und des Theaters.

181 Posner/Ware, Mengele, S. 133. 
Mengele über eigene Mittel [...] verfügen konnte, die Eichmann nie hatte. [Eichmann] war eine tragische Gestalt." 182

Mengele hat in dieser Zeit nicht unerhebliche Unterstützung von seiner Familie erhalten. Sein Vater hat ihn mindestens einmal besucht, eventuell im Juli $1952^{183}$, und auf Umwegen schickte die Familie Holzverarbeitungsmaschinen, die Josef Mengele gewinnbringend weiterverkaufte. Daneben richtete er sich eine Tischlerei ein, in der er Holzspielzeug herstellte. ${ }^{184} 1953$ zog Mengele in ein eigenes Appartement ${ }^{185}$; auch unternahm er einige Reisen nach Paraguay, wo er durch Rudel die Nazi-Sympathisanten Werner Jung und Alejandro von Eckstein kennenlernte, letzterer ein alter Kampfgefährte des deutschstämmigen paraguayanischen Diktators Alfredo Stroessner. Jung war außerdem Niederlassungsleiter der Ferreteria Paraguay SA, die eine ganze Reihe deutscher Werkzeug- und Maschinenfabriken vertrat, darunter auch die Firma Mengele. Finanziell litt er keinen Mangel, zehn Jahre nachdem er Auschwitz verlassen hatte, lebte Mengele wieder in beachtlichem Wohlstand. „Helmut Gregor" war ein geachtetes Mitglied der deutschen Kolonie von Buenos Aires, lebte nach einem erneuten Umzug in einer Haushälfte in dem vorwiegend deutschen Vorort Olivos ${ }^{186}$ und leistete sich ein Auto, einen Borgward Isabella.

Weniger positiv entwickelten sich Mengeles familiäre Verhältnisse: Seine Frau Irene wollte endlich die Scheidung, die am 25. März 1954 durch das Landgericht Düsseldorf ausgesprochen wurde. ${ }^{187}$ Nun war Josef Mengele also wieder ungebunden - genau wie seine Schwägerin Martha, die Witwe von Josefs 1949 verstorbenem Bruder Karl, die Anspruch auf Teile des Familienvermögens hatte. Martha war eine attraktive Frau ${ }^{188}$ und die Familie fürchtete, sie würde nicht ihr Leben lang Witwe bleiben wollen und so einem Fremden das Eindringen in die Sippe ermöglichen. So kam man auf die Idee, „aus zwei Halben ein Ganzes neu zu fügen“189. In der Folgezeit entwickelte sich ein reger Briefkontakt zwischen Günzburg und Lateinamerika. An Boten bestand in den folgenden beiden Jahren kein Mangel: Mehrmals kam

182 Willem Sassen im Gespräch mit John Ware, zit. nach: Ebenda. Vgl. außerdem Völklein, Mengele, S. 241.

$183 \mathrm{Vgl}$. die Angaben von Rolf Mengele, der aber kein Datum nennt, in: Ein Name wie ein Fluch, in: Bunte, 11. 4. 1985, S. 26. Anfang Juli 1952 unterrichtete Karl Mengele den Günzburger Stadtrat, „dass ich für die nächsten 3 Wochen verreise und daher an den Sitzungen und Beratungen nicht teilnehmen kann". StAGz P/SZ/M, I - Ehemalige Stadtratsmitglieder, Mengele Karl, Schreiben an Oberbürgermeister Seitz, 5. 7. 1952. Dies ist das einzige derartige Schreiben in dieser Akte.

184 Vgl. die Angaben von Rolf Mengele in: Ein Name wie ein Fluch, in: Bunte, 11. 4. 1985, S. 26, und Posner/Ware, Mengele, S. 138. Die Tischlerei befand sich in der Avenida Constituyente Ecke Avenida San Martín, Stadtviertel Florida.

185 In der Calle Tacuari 431.

186 In der Calle Sarmiento 1875

187 Mengele hatte am 16. 11. 1953 in Buenos Aires eine Prozeßvollmacht unterzeichnet. Sta F/M, Az 4 Js 340/68, Erm.A., Bd. I, Bl. 243, Prozcßvollmacht für die Rechtsanwälte Dr. Wellmann und Pohlmann, Düsseldorf, 16. 11. 1953. Vgl. außerdem: Ebenda, Bl. 241, Klageschrift der Prozeßbevollmächtigten Irene Mengeles betr. Ehescheidung, 3. 2. 1954, und B1. 245-251, Sitzungsprotokoll und Ehescheidungsurteil des Landgerichts Düsseldorf, 25. 3. 1954.

188 „Tante Martha [...] war eine wunderschöne Frau“, so die Beschreibung Rolf Mengeles, zit. nach: Ein Name wie ein Fluch, in: Bunte, 11. 7. 1985, S. 28.

189 Völklein, Mengele, S. 247. 
der Vertraute der Familie in Günzburg, Hans Sedlmeier, nach Buenos Aires, gelegentlich auch Josef Mengeles Bruder Alois, einmal sogar mit seiner Frau Ruth.

Nach intensiven Vorbereitungen konnten sich Martha und Josef 1956 endlich treffen: Mengele flog, immer noch als Helmut Gregor, über New York nach Genf. Hans Sedlmeier nahm ihn dort in Empfang, anschließend ging es weiter in den Wintersportort Engelberg. Im dortigen Luxushotel Engel warteten bereits Martha, ihr Sohn Karl-Heinz und Rolf, der nicht wußte, daß es sich bei „Onkel Fritz" aus Übersee um seinen Vater handelte, von dem er glaubte, er sei im Krieg vermißt. ${ }^{190}$ Zehn Tage hielt sich Mengele in der Schweiz auf und verbrachte seinen Skiurlaub mit seinem Sohn, dem nicht verborgen blieb, „daß Onkel Fritz sehr nett zu Tante Martha ist"191. Anschließend scheint sich Mengele kurz in Günzburg aufgehalten zu haben.

Völklein datiert diesen Besuch, gestützt auf eine Aussage Hans Sedlmeiers vom Dezember 1984, wohl fälschlich auf Anfang der 1950er Jahre. Anlaß sei die Vorbereitung der Scheidung gewesen; außerdem sei Mengele nach Wiesbaden gefahren, um sich mit ehemaligen Kollegen aus Verschuers Frankfurter Institut zu treffen. ${ }^{192}$ Von einem solchen Besuch Mengeles in Günzburg, allerdings „nach seiner Ehescheidung "193, sprach Sedlmeier bereits in einer Aussage von 1971. Dieser spätere Termin scheint auch wahrscheinlicher: Mengeles Anwesenheit war für die Regelung der Scheidung nicht nötig ${ }^{194}$, und er besaß zunächst keinen Reisepaß - ohne diesen hätte er aber nicht nach Europa reisen können. Erst im April 1955 beantragte er einen Paß für Nicht-Argentinier, der nur 120 Tage gültig war und auf dessen Ausstellung er fast ein Jahr warten mußte. ${ }^{195}$ Deshalb ist es wahrscheinlich, daß Mengele erst im Anschluß an seinen Winterurlaub Günzburg besucht hat; dies entspricht auch den Angaben Rolf Mengeles, auf die sich Posner und Ware bei ihrer Darstellung stützen und wird außerdem durch die Angaben in einem Artikel der Günzburger Zeitung aus dem Jahr 1964 gestützt, in dem es unter Berufung auf Alois Mengele heißt, daß Josef sich 1956 für einen Tag in Günzburg aufgehalten habe. ${ }^{196}$ Rolf Mengele berichtet weiterhin, sein Vater habe in München einige seiner Fluchthelfer besucht, sei dort in einen Verkehrsunfall verwickelt und von der Polizei wegen seiner Papiere befragt worden. Karl Mengele habe der Polizei dann etwas Geld gegeben, „um das mit dem Unfall zu vergessen“197.

Zurück in Buenos Aircs machte sich Josef Mengele daran, Vorbereitungen für die Hochzeit zu treffen. Dazu benötigte er eine Geburtsurkunde, die er als „Helmut Gregor" aber nicht vorweisen konnte. Also begab sich Mengele im Sommer 1956 mit seinen Papieren zur deutschen Botschaft in Buenos Aires, erklärte, er sei 1949 unter falschem Namen nach Argentinien eingereist und beantragte einen amtlichen Identitätsnachweis. In Deutschland wurde ein Josef Mengele zu diesem Zeitpunkt

190 Vgl. die Angaben Rolf Mengeles in: Ein Name wie ein Fluch, in: Bunte, 11. 7. 1985, S. 28.

191 Ebenda.

192 Vgl. Völklein, Mengele, S. 244-246.

193 Sta F/M, Az 4 Js 340/68, Erm.A., Bd. VII, Bl. 81, Aussage Hans Sedlmeier, 9. 12. 1971, Hervorhebung S.K.

194 Vgl. die Prozeßvollmacht, S. 51.

195 Vgl. Posner/Ware, Mengele, S. $142 \mathrm{f}$.

196 Vgl. Die zwei Gesichter des KZ-Arztes Mengele, in: GZ, 25. 7. 1964.

197 Zit. nach: Posner/Ware, Mengele, S. 144. 
nicht gesucht. Weder die Botschaft in Buenos Aires noch das Bonner Auswärtige Amt, das den Antrag prüfte, kamen auf die Idee, den Namen dieses Mannes, der ganz offensichtlich etwas zu verbergen und jahrelang unter falschem Namen im Exil gelebt hatte, mit den Listen der gesuchten Kriegsverbrecher zu vergleichen. So erhielt Mengele am 11. September 1956 den gewünschten Identitätsnachweis, zusammen mit seinem neuen deutschen Paß.198

Wenige Wochen später, im Oktober, trafen Martha und ihr Sohn Karl-Heinz in Buenos Aires ein. Mengele hatte mittlerweile ein Haus gekauft ${ }^{199}$, und im November erhielt er auch von den argentinischen Behörden problemlos einen neuen Ausweis auf seinen richtigen Namen. ${ }^{200}$ Am 1. Oktober 1957201 trat Josef Mengele als Mitgesellschafter in die Firma FadroFarm ein, die sich mit der Herstellung und Entwicklung von Tuberkulose-Medikamenten beschäftigte. Die Beteiligungssumme von wahrscheinlich einer halben Million Pesos (was etwa dem gleichen Wert in DM entsprach) kam zum größten Teil aus Günzburg, außerdem hatte Mengele zuvor die Spielzeugwerkstatt verkauft.

Mengeles wirtschaftliche Stellung war gesichert, er hatte ein Haus erworben, er lebte offen unter seinem richtigen Namen - der Hochzeit mit Martha stand nichts mehr im Wege, und am 28. Juli 1958 heirateten die beiden in Nueva Helvecia in Uruguay. Wenig später, am 29. September 1958, erteilte Mengele seiner Frau Generalvollmacht zur Regelung aller Angelegenheiten und Rechtsgeschäfte. ${ }^{202} \mathrm{Zu}$ diesem Zeitpunkt wußte er bereits, daß die ruhigen Tage trauten Familienlebens wahrscheinlich gezählt waren, noch ehe sie richtig begonnen hatten.

Am 3. August 1958, also genau fünf Tage nach Mengeles Hochzeit, erstattete der Schriftsteller Ernst Schnabel Strafanzeige gegen Josef Mengele. Die zunächst ermittelnde Memminger Staatsanwaltschaft bat die Günzburger Stadtpolizei um diskrete Amtshilfe bei den Ermittlungen - mit dem Ergebnis, daß spätestens Ende August die Familie Mengele über das laufende Verfahren unterrichtet war. ${ }^{203}$

Ende August hatte die Staatsanwaltschaft Freiburg i. Br. die Ermittlungen übernommen und erließ am 25. Februar 1959 den ersten Haftbefehl gegen Josef Mengele. Wiederum funktionierte der Informationsfluß: Wenige Tage später teilte Mengele seinen Mitteilhabern bei FadroFarm völlig überraschend mit, daß er seinen Anteil an der Firma verkaufen werde: „Er verlasse das Labor und auch das

198 Vgl. Völklein, Mengele, S. 249, und Posner/Ware, Mengele, S. 145.

199 Erneut in dem Villenvorort Olivos, Virrey Vertiz 970.

200 Sta F/M, Az 4 Js 340/68, HandA., Bd. II, Bl. 71, Note des Argentinischen Außen- und Kultusministeriums an die Deutsche Botschaft in Buenos Aires, 25. 10. 1960.

201 Aus einer Selbstauskunft der Firma „FADROFARM [...] Herstellung und Zubereitung von Drogen, Arzneien und medizinischen Spezialitäten“: „Unser Betrieb [...] wurde durch Dr. Ernesto Timmermann, Dr. José Mengele und Heinz Truppel verstärkt, die am 1. Oktober 1957 in die Firma eintraten. [...] Herr Mengele ist Dr. der Chemie, gebürtiger Deutscher, verheiratet, 49 Jahre alt." Sta F/M, Az 4 Js 340/68, HandA., Bd. II, Bl. 73, Dossier der VERITAS - Kaufmännische Auskunft für Zwecke der Kreditgewährung, 24. 8. 1960. Völklein sowie Posner und Ware nennen verschiedene andere Daten. Vgl. Völklein, Mengele, S. 250, und Posner/Ware, Mengele, S. 148. Die zeitnahe Angabe in der Selbstauskunft der Firma erscheint glaubwürdig.

202 Sta F/M, Az 4 Js 340/68, Erm.A., Bd. XXXVI, Bl. 1-6, Generalvollmacht des Herrn José MENGELE an seine Ehefrau Marta WILL-MENGELE, 29. 9. 1958.

203 Vgl. S. 121. 
Land" 204 , so die Erklärung des angeblich sichtlich niedergeschlagenen und sogar verängstigten Mengele, „wir werden uns nie wiedersehen“205. Kurz darauf verließ er Argentinien, während Martha und ihr Sohn Karl-Heinz noch einige Zeit in Buenos Aires blieben, bevor sie 1961 wieder nach Europa zurückkehrten. ${ }^{206}$ Ohnehin konnte sich Mengele seit dem Sturz Peróns 1955 nicht mehr der uneingeschränkten Protektion höchster argentinischer Stellen sicher sein. ${ }^{207}$ In Paraguay dagegen verfügte er mit Werner Jung und Alejandro von Eckstein seit längerer Zeit über einflußreiche Bekannte, und auch Hans-Ulrich Rudel zählte zu den Freunden des deutschstämmigen Diktators Stroessner. Außerdem hatte das Land nicht nur kein Auslieferungsabkommen mit der Bundesrepublik, sondern die Verfassung verbot ausdrücklich die Auslieferung eigener Staatsbürger. ${ }^{208}$ Wenn es Mengele also gelang, die paraguayanische Staatsbürgerschaft zu erlangen, konnte er sich vor Auslieferungsanträgen der deutschen Justiz relativ sicher fühlen. Werner Jung und Alejandro von Eckstein hatten keine Bedenken, ihm als Zeugen zu bescheinigen, daß er seit fünf Jahren im Land lebe. Am 29. November erhielt er die Einbürgerungsurkunde auf den Namen José Mengele. ${ }^{209}$

Mengele verbarg sich im äußersten Süden des Landes. Zunächst kam er bei dem belgischen Nazisympathisanten Armand Reinaerts unter, der in der Grenzstadt Encarnación das Gasthaus Tirol betrieb. ${ }^{210}$ Seit Mai 1959 versteckte er sich dann auf der Farm Alban Krugs, eines Freundes Hans-Ulrich Rudels. Die Farm lag abgelegen in der Nähe des Städtchens Hohenau, etwa 65 Kilometer nordöstlich von Encarnación, und bot Mengele für die nächsten eineinhalb Jahre ein sicheres Versteck. $^{211}$

Im April 1960 traf sich Mengele mit Martha und Hans Sedlmeier in Asunción, um die Modalitäten der weiteren finanziellen Unterstützung und möglichst sichere Kommunikationswege zu vereinbaren. Anschließend verbrachten sie einige Tage zusammen in Reinaerts' Hotel Tirol, bevor Martha und Sedlmeier nach Buenos Aires zurückkehrten. ${ }^{212} \mathrm{Es}$ war das letzte Mal, daß Josef und Martha Mengele sich

204 Aussage Heinz Truppels, zit. nach: Posner/Ware, Mengele, S. 155.

205 Aussage der Sekretärin Elsa Haverich, zit. nach: Posner/Ware, Mengele, S. 155. Vgl. außerdem Völklein, Mengele, S. 256.

$206 \mathrm{Karl}-\mathrm{Heinz}$ besuchte danach ein Internat im schweizerischen Montreux, Martha mietete zunächst ein Appartement in Zürich-Kloten und zog 1962 nach Meran/Südtirol.

207 Die Polizei von Buenos Aires scheint sogar wegen angeblicher ärztlicher Hilfeleistung ohne Approbation gegen ihn ermittelt zu haben, die genauen Hintergründe dieser Ermittlungen sind jedoch unklar. Vgl. Posner/Ware, Mengele, S. 149.

208 Vgl. Völklein, Mengele, S. 257, und Posner/Ware, Mengele, S. 155-158.

209 Völklein, Mengele, S. 257f., und Posner/Ware, Mengele, S. 160-167.

210 In einer der vielen Legenden, die sich um die Person Mengeles ranken, spielt ebenfalls ein Hotel „Tyrol“ eine Rolle: Vgl. S. 70.

211 Posner und Ware schreiben, Mengele habe sich in einem Gebiet namens Alto Paraná aufgehalten, das die deutschen Einwanderer wegen der Berge Nueva Bavaria genannt hätten (Posner/Ware, Mengele, S. 157f.); Völklein übernimmt dies (Völklein, Mengele, S. 256); Encarnación und Hohenau liegen aber nicht in der Provinz Alto Paraná, sondern in der Provinz Itapúa, und auch ein angebliches Länderdreieck Paraguay-Brasilien-Uruguay (ebenda) existiert nicht - zwischen Uruguay und Paraguay liegen ca. 300 Kilometer argentinisches Gebiet. Ein tatsächliches Dreiländereck Paraguay-Brasilien-Argentinien liegt rund 250 Kilometer nordöstlich von Encarnación bei der Grenzstadt Ciudad del Este.

212 Vgl. Völklein, Mengele, S. $259 \mathrm{f}$. 
sahen. Denn wenige Wochen später ereignete sich etwas, das Mengele wesentlich stärker beunruhigte als der deutsche Haftbefehl und die Auslieferungsanträge, die die deutsche Justiz mittlerweile an Argentinien gerichtet hatte: Am 11. Mai 1960 entführte der israelische Geheimdienst Adolf Eichmann von Buenos Aires nach Jerusalem.

Mengele war sich der Tatsache bewußt, daß seine Situation sich nun grundlegend geändert hatte. Nach elfjähriger Pause (die den elf Jahren relativer Sicherheit in Argentinien und zunächst auch in Paraguay entsprechen) begann er wieder, Tagebuch zu führen. Zwar schützte ihn seine paraguayanische Staatsbürgerschaft vor einer Auslieferung an Deutschland - wer aber garantierte ihm, daß er nicht der nächste auf der Liste des israelischen Geheimdienstes war?213 Sein Ausweis lautete auf seinen tatsächlichen Namen, und zu viele Leute wußten, wo er sich aufhielt. Mitte Oktober 1960 verließ Mengele das Land in Richtung Brasilien, ausgestattet mit einem brasilianischen Ausweis auf den Namen Peter Hochbichler. Alban Krug warnte ihn zum Abschied: „Für dich ist der Krieg noch nicht vorbei, sei vorsichtig.“214

Erneut war es Hans-Ulrich Rudel gewesen, der die Flucht organisiert hatte. Erster Ansprechpartner Mengeles in Brasilien war Wolfgang Gerhard215, der Vertreter des Kameradenwerks in São Paolo. Gerhard verstand es als persönlichen Vertrauensbeweis Rudels, „dem Herrn Dr. Dr. Mengele zu Diensten sein zu dürfen“216. Weniger erfreulich waren die Nachrichten, die Mengele zu dieser Zeit aus Europa erreichten: Im Rahmen der Vorermittlungen zum Frankfurter Auschwitzprozeß kamen durch Aussagen von Opfern und Tätern immer mehr Details über Mengeles Greueltaten in Birkenau ans Licht, und schließlich übernahm die Frankfurter Staatsanwaltschaft die Ermittlungen. Der Fall Mengele rückte ins Bewußtsein der Öffentlichkeit. Von nun an erschienen in rascher Folge eine unübersehbare Menge an Zeitungs- und Zeitschriftenartikeln, Büchern und Fernsehreportagen über Mengele und die erfolglose Suche nach ihm. Kaum etwas davon war seriös oder gab, objektiv betrachtet, über mehr Auskunft als über die blühende Phantasie der Verfasser. Und doch hielten diese Berichte Mengele, seine Familie und seine Helfer in ständiger Unruhe. 217

Bald zeigte sich Mengele mit seinem Leben in São Paolo unzufrieden; in seinem Tagebuch beklagte er die stupide Hilfsarbeit in Gerhards Textildruckerei, die

213 Tatsächlich scheint der Mossad versucht zu haben, nach oder parallel zu der Festsetzung Eichmanns auch nach Mengele zu suchen. Vgl. dazu Posner/Ware, Mengele, 168-185. Möglicherweise kam der Geheimdienst Mengele in Brasilien 1960 oder 1961 ziemlich nahe. Vgl. dazu und zu den Gründen für die De-facto-Einstellung der Suche des Mossad die unterschiedlichen Versionen von Isser Harel und Zvi Aharoni, in: Posner/Ware, Mengele, S. 225-236.

214 Tagebucheintrag Mengeles, zit. nach: Völklein, Mengele, S. 262.

215 Geb. 1925 in Leibnitz (Österreich); stammte aus einer überzeugt nationalsozialistischen Familie und war Führer in der Hitlerjugend; wanderte 1949 mit seiner Mutter und seiner Verlobten nach Brasilien aus; das erste der insgesamt vier Kinder erhielt 1958 den Namen Adolf; vertrieb in Brasilien den „Reichsruf“, die Zeitschrift der 1952 vom Bundesverfassungsgericht verbotenen Sozialistischen Reichspartei (SRP) und den "Reichsruf“ des Kameradenwerks. Vgl. Völklein, Mengele, S. 263.

216 Brief Wolfgang Gerhards an Hans-Ulrich Rudel, 30. 12. 1960, zit. nach: Völklein, Mengele, S. 263.

217 Vgl. Völklein, Mengele, S. 265. 
"gleich nach dem Tütenkleben" 218 komme. Schlimmer noch aber war für ihn die „Gesamtsituation: Enge, Eintönigkeit, Primitivität, Unruhe, Formlosigkeit, die letzten Endes trotz all des Negativen keinerlei Gewähr für Sicherheit bietet. “219 In seinem Tagebuch dominieren von nun an bis zu seinem Tod „Isolation, Eitelkeit, Narzißmus und Bosheit" 220 . Die Eintragungen sind voll von „Selbstbespiegelung und Selbstmitleid“, und immer wieder befaßte sich Mengele in extenso „mit dem eigenen seelischen Befinden, mit seiner Gesundheit, mit fehlender Unterstützung von zu Hause, mit seinem Verdruß über den einfältigen Freundeskreis und mit den ,großen deutschen Schicksalsfragen" "221. Die Probleme und Empfindungen anderer, wie etwa seiner Familie, seines Sohnes Rolf oder seiner Unterstützer, waren ihm gleichgültig. Mit Rolf stand Mengele in brieflichem Kontakt und zeigte sich ein ums andere Mal enttäuscht von der Entwicklung seines Sohnes, der mittlerweile um die Identität seines Vaters wußte und für den diese Enthüllung einer Katastrophe gleichgekommen war. Josef Mengele hatte bei Rolf „so verschiedene Korrekturen anzubringen gehofft", welche die „spießbürgerliche und pseudokosmopolitische

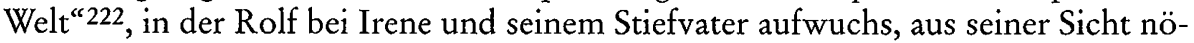
tig erscheinen ließ. Mengele wurde im Laufe der Zeit zu einem auch für seinen anfangs so begeisterten Gastgeber nur noch schwer erträglichen Hausgenossen. Als Gerhard im Deutschen Club von São Paolo eines Abends dem - politisch gleichgesinnten - ungarischen Ehepaar Gitta und Geza Stammer ${ }^{223}$ begegnete, das ein landwirtschaftliches Anwesen besaß, empfahl er ihnen Peter Hochbichler (alias Mengele) wärmstens als erfahrenen Rinderzüchter. Geza war durch seine Arbeit als Landvermesser häufig abwesend, einer wie der angebliche Schweizer Hochbichler, der außer Kost und Logis keinen Lohn verlangte, war ihnen deshalb durchaus willkommen. ${ }^{224}$

In der zweiten Jahreshälfte 1961 zog Mengele als Verwalter auf die Fazenda der Stammers. Dort ging er zurückgezogen seiner Arbeit nach und vermied jeden Kontakt nach außen. Einzig Gerhard besuchte Mengele regelmäßig und brachte Geld, Post und Zeitungen. Die Stammers erfuhren bald, wen sie da tatsächlich auf ihrer Farm beschäftigten: Gitta erkannte Peter Hochbichler auf einem MengeleFoto wieder, das am 27. Januar 1962 anläßlich des Jahrestages der Befreiung von Auschwitz in einer Zeitung abgedruckt worden war. Mengele gab sich schließlich

218 Tagebucheintrag Mengeles, 12. 1. 1961, zit. nach: Völklein, Mengele, S. 268.

219 Ebenda.

220 So der Historiker Norman Stone, zit. nach: Posner/Ware, Mengele, S. 271. Stone war einer der Gutachter, die 1985 die Echtheit von Mengeles Nachlaß untersuchten.

221 Völklein, Mengele, S. 268.

222 Tagebucheintrag Josef Mengeles vom 23. 11. 1960, zit. nach: Völklein, Mengele, S. 266.

223 Gitta (geb. 1920) und Geza (geb. 1923) Stammer, 2 Söhne; nach dem Zweiten Weltkrieg Emigration aus dem kommunistischen Ungarn zunächst nach Österreich, im Dezember 1948 schließlich nach Brasilien; Tätigkeit Gezas als Ingenieur zunächst bei verschiedenen Firmen; später selbständiger Landvermesser; 1959 Kauf einer rund 15 Hektar großen Farm etwa 250 Kilometer von São Paolo (bei Araraquara); Anbau von Obst, Kaffee und Reis und kleine Rinderzucht; bei Völklein wird nicht klar, welches Araraquara gemeint ist: Es gibt eine größere Stadt dieses Namens ziemlich genau 250 Kilometer nordwestlich und eine kleinere gut 280 Kilometer nördlich von São Paolo; Völklein spricht von 350 Kilometern nordwestlich. Vgl. Völklein, Mengele, S. 269.

224 Vgl. Völklein, Mengele, S. 268f., und Posner/Ware, Mengele, S. 203 f. 
zu erkennen. Mit den Verbrechen, die man ihm vorwarf, habe er allerdings nichts zu tun. ${ }^{225}$

Das Ehepaar Stammer entschloß sich, aus der Sache Kapital zu schlagen: Geza fuhr nach São Paolo zu Gerhard und machte ihm klar, daß - sollte Mengele bei ihnen bleiben - es nötig sei, eine besser abgeschirmte Farm zu kaufen. Natürlich müsse sich Mengele an den Kosten angemessen beteiligen. Gerhard informierte Rudel und Mengeles Familie, und schon im April stand die alte Farm zum Verkauf. Wie immer beunruhigte Mengele jede Veränderung; hinzu kam diesmal noch die Nachricht von Eichmanns Hinrichtung am 1.Juni 1961 in Tel Aviv. Wenig später begann der Umzug: Die neue Zuflucht, die 45 Hektar große Kaffeeplantage Santa Luzia lag 100 Kilometer nordwestlich von São Paolo, nahe des Städtchens Lindóia ${ }^{226}$; Mengele hatte sich mit 25000 US-Dollar beteiligt, außerdem kam Sedlmeier für einige Tage auf die Farm und erleichterte den Stammers ihre Entscheidung durch eine weitere Summe in US-Währung. 227

Schnell freundete sich Mengele mit seiner neuen Umgebung an. Von dem Hügel, auf dem die Farm lag, konnte er die einzige Straße kilometerweit einsehen, zusätzlich ließ er sich einen Aussichtsturm bauen. Allmählich entwickelte er außerdem „eine sehr enge und vertraute Beziehung “228 zu Gitta Stammer. Ob sich daraus auch das verschiedentlich behauptete sexuelle Verhältnis zu der Ungarin entwickelte, ist nicht eindeutig zu beantworten. Es scheint jedoch, daß sich aus dieser Affäre nie eine dauerhafte sexuelle Bczichung entwickelt hat. Mengeles Tagebucheintragungen zeigen, daß „Gitta Stammer - wenn überhaupt - wohl eher ,aus Mitleid‘ denn aus Liebe Mengele Zuwendung gezeigt hat"229. Jedenfalls blieb Mengele unzufrieden. In seinen Tagebucheinträgen klagte er über die Arbeit, die ihn langweilte und gleichzeitig an den Rand seiner physischen Kräfte brachte. Er beschwerte sich über mangelnde Anerkennung seiner Leistungen durch die Stammers und mußte dem notorisch geldknappen Geza des öfteren aushelfen; geistige Abwechslung boten nur die nach wie vor regelmäßigen Besuche Gerhards, mit dem er leidenschaftlich diskutierte, und seit Frühjahr 1963 ein Klavier. Mengele schwelgte im Selbstmitleid, das durch die wissenschaftliche Degradierung durch die Aberkennung seiner beiden Doktorgrade $1964^{230}$ noch gesteigert wurde.

225 Vgl. Völklein, Mengele, S. 269 f., und Posner/Ware, Mengele, S. 204 und 217.

226 Die geographischen Angaben bei Völklein sind ungenau: Die neue Farm lag nicht „, in Serra Negra“, das kein Gebiet, sondern eine Stadt ist, die wiederum nicht „200 Kilometer nordwestlich“, sondern ziemlich genau 100 Kilometer nördlich von São Paolo liegt; tatsächlich muß die Farm etwa 10 Kilometer entfernt von dem Städtchen Lindóia, nahe Serra Negra, gelegen haben, das Völklein "Lindonia“ nennt. Vgl. Völklein, Mengele, S. 271.

227 Vgl. ebenda, S. 270 f.

228 Völklein, Mengele, S. 271.

229 Ebenda. Posner und Ware vertreten hier eine andere Ansicht und behaupten, das Verhältnis zwischen Gitta und Mengcle hätte sogar bis 1974 angedauert. Vgl. Posner/Ware, Mengele, S. $220 \mathrm{f}$.

230 Die Universität München hatte bereits 1960 die Initiative ergriffen, dennoch dauerte es noch bis zum 23. 9. 1963, bis Mengele seine beiden Doktortitel rechtsgültig aberkannt wurden. Vgl. F/M, Az 4 Js 340/68, HandA., Bd. II, Bl. 34, Brief des Rektors der Universität München an die Staatsanwaltschaft Freiburg i. Br., 13.10. 1960, und ebenda, B1. 43, Abschrift eines Briefes des Rektors der Universität München an den Rektor der JohannWolfgang-Goethe-Universität Frankfurt, 9. 12. 1960. 
Seit seiner Flucht aus Paraguay deutete nichts darauf hin, daß irgend jemand ahnte, wo er sich aufhielt. Dennoch kam es 1967 zu einem weiteren Ortswechsel. Die Wahl fiel auf ein geräumiges Haus in Jardin Luciana bei Caieiras, rund 30 Kilometer nordwestlich von São Paolo. Bis zum endgültigen Einzug dauerte es allerdings noch bis zum April 1968, nicht zuletzt deshalb, weil sich die Spannungen zwischen dem unzufriedenen Mengele und den Stammers mittlerweile verschärft hatten. Gerhard informierte erneut die Mengeles in Günzburg und bat gleichzeitig die Stammers, noch durchzuhalten - schließlich seien sie auf Mengeles Geld beim Kauf des neuen Hauses angewiesen. 231

Die Stammers ließen sich also noch einmal bestechen, und gleichzeitig zeichnete sich eine unerwartete Besserung der Situation ab. Gerhard hatte 1965, erneut im Deutschen Club, Wolfram und Liselotte Bossert ${ }^{232}$ kennengelernt. Gerhards Landsmann Bossert erwies sich schnell auch als Gesinnungsgenosse, außerdem liebte er die deutsche Klassik in Musik und Literatur. Mengele und „Musikus“ (wie Bossert in seinem Freundeskreis genannt wurde) paßten gut zusammen. Im Oktober 1968 stellte Gerhard die Bosserts und „Peter Hochbichler" einander vor, und von nun an verbrachte Mengele seine Freizeit am liebsten mit dem „Musikus“. Die Unterhaltungen, Spaziergänge, Naturstudien, Schallplattenkonzerte und gemeinsamen Lektüreabende wollte er bald nicht mehr missen, und Bossert ertrug seine schulmeisterlichen Belehrungen klaglos und teilte seine rassistische Weltanschauung. Als die Bosserts erfuhren, wer Peter Hochbichler wirklich war, war das für beide kein Grund, den Kontakt abzubrechen. Die zeitweilige Entlastung, die das Verhältnis zu den Stammers durch diese Freundschaft erhielt, dürfte es überhaupt erst möglich gemacht haben, daß Mengele noch weitere sechs Jahre, bis 1975, mit den Stammers unter einem Dach leben konnte.233

Grundsätzlich gebessert hat sich das Verhältnis zwischen Mengele und den Stammers nicht. Mengele litt unter extremen Stimmungsschwankungen, auch ein zweiter Besuch Sedlmeiers brachte keine Lösung - zumal er diesmal kein Geld im Gepäck hatte. Sedlmeier plante zusammen mit Rudel, Mengele in Bolivien unterzubringen bei Klaus Barbie ${ }^{234}$. Mengele und Gerhard lehnten dies mit dem Hinweis, daß sowohl Rudel als auch Barbie vermutlich vom israelischen Geheimdienst beobachtet würden, strikt ab. Außerdem wollte Mengele sich keinesfalls von Gerhard und den Bosserts trennen. Gleichzeitig nahmen die Auseinandersetzungen mit den Stam-

231 Vgl. Völklein, Mengele, S. 275.

232 Liselotte (geb. 1927) und Wolfram (geb. 1925), 2 Kinder (1964/1966); beide aus Bruck an der Mur in der Steiermark; Wolfram war 1942 als 17-jähriger der NSDAP beigetreten; von Beruf Techniker; während des Krieges Dienst bei einem V2-Raketenkommando. Vgl. Völklein, Mengele, S. 275.

233 Vgl. Völklein, Mengele, S. 275f., und Posner/Ware, Mengele, S. 275-281.

234 Klaus Barbie, geb. 1913, der „Schlächter von Lyon“; von 1942-1944 als SS-OStuf Gestapochef von Lyon; dort verantwortlich für die Deportation von Juden und für die Folterung und Ermordung des führenden Résistance-Mitgliedes Jean Moulin; 1947, 1952 und 1954 in Abwesenheit von französischen Gerichten zum Tode verurteilt; 1947-1951 als Agent für den amerikanischen Geheimdienst CIC tätig; 1951 Emigration mit Hilfe des CIC nach Bolivien; 1957 Annahme der bolivianischen Staatsbürgerschaft unter dem Namen Klaus Altmann; 1974 Auslieferungsantrag der franz. Regierung; 1983 von der mittlerweile amtierenden demokratischen Regierung Boliviens an Frankreich ausgeliefert; 1987 zu lebenslanger Haft verurteilt; 1991 in Haft verstorben. 
mers an Häufigkeit und Schärfe zu, und Mengele wurde immer depressiver. Je mehr in der deutschen Öffentlichkeit über die Verbrechen des Nationalsozialismus bekannt wurde, desto weniger konnte er seine Vergangenheit verdrängen. Gegenüber der Familie in Günzburg besaß er nicht mehr die uneingeschränkte Deutungshoheit über die Ereignisse in Auschwitz, was sich in einer von ihm beklagten zunehmenden Distanzierung der Familie äußerte. So weit, daß die Familie den unbequemen Verwandten in Südamerika hätte fallen lassen, ist diese Distanzierung freilich nie gegangen. Auch er selbst wurde von der Vergangenheit geplagt: „Statt erquickenden Schlafes quälen böse Gesichter und Träume den in tiefster Seele so Müden"235, und so sind „die späten Stunden des Tages [...] die schwersten, [...] voll Scheu ins Bett zu gehen, um den Großteil der Nacht dort schlaflos zu liegen. Die Schlaflosigkeit zitiert die Gespenster"236.

1971 kehrte Wolfgang Gerhard nach Österreich zurück. Er überließ Mengele zwar trotz des enormen Altersunterschiedes von 14 Jahren seine Ausweispapiere, die mit einem neuen Foto versehen wurden ${ }^{237}$, doch der Verlust des Vertrauten, des Geld- und Briefboten und des verläßlichen Helfers in allen Krisen wog weit schwerer. Diese Rolle mußte nun Wolfram Bossert übernehmen. Anfang 1975 war an ein weiteres Zusammenleben mit den Stammers nicht mehr zu denken: Geza wohnte bereits seit geraumer Zeit in einem Hotel, und auch weitere 5000 US-Dollar, die Sedlmeier von Karl-Heinz Mengele überbrachte, halfen nicht mehr weiter. Mit dem Geld, das Mengele aus dem Verkauf der Farm bei Serra Negra zustand, wurde ein kleines, vergleichsweise bescheidenes Haus in einem eher ärmlichen Viertel von São Paolo erworben: Mengele hatte die letzte Station seiner Flucht erreicht. Seine Depressionen nahmen zu, er ertrug die Einsamkeit nicht, zerstritt sich mit seinen Haushaltshilfen und den Nachbarn. Ihm blieben nur noch die Bosserts und die Hoffnung, seinen Sohn Rolf, den er 1956 in der Schweiz zum letzten Mal gesehen hatte, noch einmal wiederzusehen. 238

Auch Rolf wollte den Vater treffen, von dem er keine Vorstellung hatte und von dem er nur die Kritik und die Bevormundung aus den Briefen kannte. Er wollte den Mann konfrontieren und Antworten von ihm fordern. 1973 schrieb er ihm, daß er ihn sehen und sprechen wolle. Mengele war einverstanden: Er solle kommen, aber nur ohne „schablonenhafte Vorurteile, beeinflußtes Wunschdenken, kritikloses Simplifizieren, billiges Ressentiment und belehrende Überheblichkeit“239. Es sei klar, daß man "ohne hinreichende ,Reife', ,Größe und ,Augenmaß' [...] gewisse ,historische Vorgänge" auf sich beruhen lassen" ${ }^{240}$ solle. Schon in einem früheren Brief hatte er klar gemacht, daß er glaubte, von Rolf „Verständnis und Nachempfinden meines Lebenslaufs nicht erhoffen“ zu können und deshalb „nicht die geringste innere Veranlassung [sab], irgendwelche Entscheidungen, Handlungen und Verhal-

235 Tagebucheintrag Mengeles, zit. nach: Von Reue keine Spur, in: Bunte, 18. 7. 1985, S. 111.

236 Tagebucheintrag Mengeles, 10. 6. 1974, zit. nach: Völklein, Mengele, S. 287. Vgl. außerdem: Ebenda, S. 276-287.

237 Vgl. Carteira de identidade para estrangeiro permanente auf den Namen Wolfgang Gerhard, Faksimile in: Kubica, Mengele, S. 427.

$238 \mathrm{Vgl}$. Völklein, Mengele, S. 288-290 und S. 296.

${ }^{239}$ Brief Mengeles an seinen Sohn Rolf, zit. nach: So entkam mein Vater, in: Bunte, 20. 6. 1985, S. 33.

240 Ebenda. 
tensweisen über die sachliche Begründung hinaus zu ,rechtfertigen'. [...] Meine Toleranz hat wirklich ein exaktes Limit“, schrieb Mengele seinem Sohn, „nämlich dort, wo es um undiskutierbare traditionelle Werte geht und wo ich Gefahren für die mir Nahestehenden oder meine völkische Gemeinschaft befürchten muß"241.

Rolf Mengele kam dennoch, allerdings erst 1977, ein Jahr, nachdem sein Vater im Mai 1976 einen leichten Schlaganfall erlitten hatte. Die leichten Lähmungserscheinungen und Sprachstörungen hatten sich nach kurzer Zeit im Krankenhaus wieder gelegt, und in der Klinik war auch niemandem aufgefallen, daß der Patient wesentlich älter sein mußte als auf dessen Personalausweis vermerkt. Dennoch lebte Mengele nun in der ständigen Angst, das nächste Mal könnte nicht so glimpflich für ihn ausgehen. Rolf hatte die Hoffnung auf Antworten mittlerweile aufgegeben - er fuhr „aus Mitleid“242. Am 11. Oktober 1977 traf der Sohn ein. Zwei Nächte lang diskutierten beide miteinander, auf der einen Seite der eher linksliberale Sohn, auf der anderen Seite der untergetauchte NS-Verbrecher, der immer noch an die alten Ideologien glaubte und immer noch von der Ausmerze unwerten Lebens sprach. Mengele erzählte seine Lebensgeschichte - über Auschwitz verlor er kein Wort. Rolf gab auf. Am 19. Oktober, nach insgesamt acht Tagen, flog er zurück nach Deutschland.243

16 Monate später, am 7. Februar 1979, erlitt Josef Mengele während eines Sommerurlaubs mit der Familie Bossert in dem brasilianischen Badeort Bertioga beim Schwimmen einen weiteren Schlaganfall und ertrank. Bereits am nächsten Tag wurde er auf dem Friedhof Nossa Senhora do Rosario in Embu, einem Vorort von São Paolo, unter dem Namen Wolfgang Gerhard beerdigt. ${ }^{244}$

Wolfram Bossert verständigte die Familie in Günzburg brieflich vom Tod des "gemeinsamen Freundes“245. Weiter schrieb er: „Wir glauben uns auch mit Ihnen eines Sinnes, wenn wir die Geheimhaltung weiterhin wie bisher aufrecht erhalten wollen. Nicht nur um persönliche Unannehmlichkeiten zu vermeiden, sondern auch um die Gegenseite weiterhin Geld und Mühe [...] verschwenden zu lassen."246 Die Familie war erleichtert und beschloß tatsächlich, Josefs Tod geheimzuhalten. Dabei spielte nicht nur die Schadenfreude über die vergeblichen Fahndungsbemühungen eine Rolle, sondern auch der Schutz der Helfer, die nicht zum engsten Familienkreis gehörten (wie etwa die Schlüsselfigur Sedlmeier). Die Hilfe für den gesuchten NS-Verbrecher war juristisch betrachtet Strafvereitelung und als solche bis zu einer Verjährungsfrist von fünf Jahren strafbar. Schließlich war es Sedlmeier selbst, der „in einem Hotel betrunken damit [prablte], daß er jahrelang nach Südamerika gefahren sei und Dr. Mengele Geld überbracht habe“247.

241 Brief Mengeles an seinen Sohn Rolf, zit. nach: So entkam mein Vater, in: Bunte, 20. 6. 1985, S. 33 .

242 Rolf Mengele in: Von Reue keine Spur, in: Bunte, 18. 7. 1985, S. 110.

243 Vgl. ebenda, S. 114 f.; Völklein, Mengele, S. 296-300, und Posner/Ware, Mengele, S. 329-342. Rolfs Version, die er 1985 der Illustrierten Bunte erzählte, wird hinsichtlich der Konfrontationen zwischen Vater und Sohn von Wolfram Bossert bestätigt. In Mengeles Tagebüchern finden sich dazu keine Hinweise, er handelt den Besuch seines Sohnes, der ihn emotional sehr berührt haben muß, in denkbar knappen Worten ab.

244 Vgl. Völklein, Mengele, S. 301-306, und Posner/Ware, Mengele, 346-348.

245 Schreiben Wolfram Bosserts an Hans Sedlmeier, zit. nach: Völklein, Mengele, S. 307.

246 Ebenda.

${ }^{247} \mathrm{~F} / \mathrm{M}, \mathrm{Az} 4 \mathrm{Js}$ 340/68, FO Deutschland SO, Durchsuchungen und Ermittlungen in Günz- 
Nach dem 27. Januar 1985, dem vierzigsten Jahrestag der Befreiung von Auschwitz, nahmen die internationalen Fahndungsbemühungen und das Medieninteresse am Fall Mengele dramatisch zu. ${ }^{248}$ Nun informierte am 6. März 1985 Sedlmeiers Gesprächspartner, ein Gießener Professor, die Staatsanwaltschaft. Gleichzeitig mehrten sich die Hinweise, die dafür sprachen, daß Mengele nicht mehr am Leben war. So erhielt etwa der zu diesem Zeitpunkt wegen rechtsterroristischer Straftaten im hessischen Butzbach einsitzende Manfred Roeder Mitte März einen Brief aus Asunción, in dem es hieß: „Wir verfolgen weiterhin die Tragikkomödie mit der Suche nach Mengele, wir kannten hier den Mann, der Mengele [...] bei sich im Haus hatte [Alban Krug].“ Der entscheidende Satz kam später: „Außerdem ist er längst tot, vor circa vier Jahren beim Schwimmen ertrunken. "249 Schließlich gelang es der Frankfurter Staatsanwaltschaft endlich, einen Durchsuchungsbefehl gegen Hans Sedlmeier zu erwirken. Am 31. Mai 1985 wurden die Beamten in Günzburg fündig: Hinter einem Schrank im Schlafzimmer entdeckten sie in einem Geheimfach Fotos, Briefe und ein verschlüsseltes Adreßbuch.

Die Polizei brauchte nur wenige Stunden, um die Spur nach São Paolo zurückzuverfolgen, und am 5. Juni250 öffneten brasilianische Ermittlungsbeamte das Grab in Embu. Brasilianische, amerikanische, israelische und deutsche Sachverständige untersuchten nun unter den gespannten Augen der Weltöffentlichkeit, ob es sich bei der exhumierten Leiche tatsächlich um diejenige Josef Mengeles handelte. Am 21. Juni wurde das Ergebnis bekanntgegeben: Die untersuchte Leiche war mit an Sicherheit grenzender Wahrscheinlichkeit die des KZ-Arztes. In der Folgezeit wurde dieses Ergebnis vielfach angezweifelt. Insbesondere die noch lebenden Opfer Mengeles argumentierten dabei verständlicherweise sehr emotional. Auch Simon Wiesenthal, der zunächst das Urteil der Expertenkommission anerkannt hatte, zweifelte bald wieder am Tod Mengeles ${ }^{251}$, doch eine zweite, ausführliche pathologische Untersuchung im Jahr 1986, die historischen und graphologischen Gutachten zu Mengeles Aufzeichnungen, Schädel-Foto-Vergleiche und schließlich eine im Jahr 1992 durchgeführte DNA-Analyse bestätigten das Resultat. ${ }^{252}$

burg, Rosenheim, Augsburg u.a., Sedlmeier Günzburg, Bl. 40, Vermerk von Oberstaatsanwalt Müller, Landgericht Gießen, 7. 3. 1985. Vgl. außerdem: Völklein, Mengele, S. $307 f$. 248 Vgl. S. 159 ff.

249 Zit. nach: Völklein, Mengele, S. $308 \mathrm{f}$.

250 Das von Völklein genannte Datum des 6. Juni ist falsch. Vgl. z.B. die Erklärung Rolf Mengeles zum Tod seines Vaters, zit. in: Rolf Mengele bestätigt den Tod seines Vaters, in: SZ, 12. 6. 1985.

251 Vgl. Wiesenthal, Recht, S. 150-153.

$252 \mathrm{Vgl}$. die forensischen Gutachten in: In the Matter of Josef Mengele 2, S. 345-418, und das

Ergebnis der DNA-Untersuchung, ebenda, S. 421-423. Vgl. außerdem: Völklein, Mengele,

S. 309-312, und Posner/Ware, Mengele, S. 378-391. 